\title{
Gobiernos locales en Canadá y en España: lejos, pero no tanto
}

\section{Local governments in Canada and Spain: far, but not that much}

\author{
Francisco Velasco Caballero \\ Instituto de Derecho Local. Universidad Autónoma de Madrid (España) \\ ORCID: https://orcid.org/0000-0003-1055-3939 \\ francisco.velasco@uam.es
}

\section{NOTA BIOGRÁFICA}

Catedrático de Derecho Administrativo en la Universidad Autónoma de Madrid. Entre sus líneas de investigación destacan: la Administración europea, el Derecho local y la Metodología del Derecho administrativo.

\section{RESUMEN}

El estudio compara los sistemas de gobierno local en Canadá y en España. El análisis se centra en cinco ámbitos significativos: estructura de la planta local; autonomía; democracia; forma de gobierno; y financiación. Aunque inicialmente se podría pensar que los regímenes locales en ambos países son muy distantes, visto con más profundidad hay tanto diferencias claras (en la planta local, las formas democráticas y la forma de gobierno) como también similitudes importantes: en el nivel de autonomía local real y en el sistema financiero.

\section{PALABRAS CLAVE}

Autonomía local; democracia local; entidades locales canadienses; gobiernos locales; financiación local; metodología comparada.

\begin{abstract}
The study compares local government systems in Canada and in Spain. The analysis focuses on five significant areas: tiers of local government; autonomy; democracy; governing bodies; and financing. Although initially one might think that local schemes in both countries are very distant, seen in more depth there are both clear differences (in the tiers of local government, the democratic arrangement and the governing bodies) as well as important similarities: in the levels of real autonomy of municipalities and as to the financial system.
\end{abstract}

\section{KEYWORDS}

Local autonomy; local democracy; canadian municipalities; local self-government; local financing; comparative methodology.

\section{SUMARIO}

INTRODUCCIÓN. 1. SIMILITUDES Y DIFERENCIAS. 1.1. FEDERALISMO. 1.2. DIVERSIDAD. 1.3. DEMOCRACIA. 2. LA PLANTALOCAL. 3. AUTONOMÍA LOCAL: COMPETENCIAS Y CONTROLES. 3.1. COMPETENCIAS. 3.2. CONTROLES. 4. DEMOCRACIA. 5. FORMA DE GOBIERNO. 6. FINANCIACIÓN. REFERENCIAS BIBLIOGRÁFICAS. 
REALA. Nueva Época - N.o 13, abril-septiembre 2020 - ISSN: 1989-8975 - DOI: 10.24965/reala.i13.10742 - [Págs. 22-46]

Gobiernos locales en Canadá y en España: lejos, pero no tanto

Francisco Velasco Caballero

\section{INTRODUCCIÓN ${ }^{1}$}

\$1 Lo que sigue es una comparación entre los sistemas de gobierno local en Canadá y en España. Sigue pautas estandarizadas de metodología comparada, con algunas cautelas y singularidades. La precisión fundamental es que los contextos analíticos de los gobiernos locales son distintos en los dos países ${ }^{2}$. En Canadá el gobierno local es en gran medida una cuestión política, que encuentra su campo de análisis principalmente en la ciencia política (local government studies). En cambio, en España prima tradicionalmente una comprensión jurídica del gobierno local. Es lo que conocemos como «régimen jurídico local» o, simplemente, como «régimen local». En Canadá se estudian los gobiernos locales como realidad social. El Derecho (las leyes municipales de las provincias y las sentencias de los tribunales) tiene una función secundaria en la investigación sobre el gobierno local. Sirve para explicar la realidad, pero recibe poca atención per se. Apenas si hay estudios académicos específicos sobre Derecho local. Y los existentes son más bien comentarios anotados -algunos muy meritorios- a las leyes municipales de las provincias ${ }^{3}$. Este marco contextual dificulta la comparación con el sistema de gobierno local en España. Pues para comprender el sistema local canadiense es necesario acceder a una literatura que presta poca atención a los datos normativos. Y esa información, conformada a partir de categorías propias de la ciencia política, ha de ser confrontada con otra realidad, la del «régimen local» español, que está sistematizada y formalizada fundamentalmente -aunque no sólo- por medio de categorías jurídicas.

Hecha la anterior precisión, lo que a continuación se expone es una comparación horizontal, entre dos sistemas de gobierno o regímenes locales ${ }^{4}$. Se observa y analiza el sistema local canadiense desde la perspectiva del régimen local español. Se utilizan, para ello, los equivalentes funcionales (Esteve, 2010: 295; De la Sierra, 2016: 73). Esto es, con independencia de la denominación y calificación que cada fenómeno local reciba en su país, la comparación se hace entre las realidades institucionales que cumplen una función simétrica en cada país. Así, si bien en Alberta se habla del chief elected official, la comparación se tiene que trabar necesariamente con el alcalde español. Pues, aunque sus atribuciones y relevancia política son muy distintas, su posición funcional es simétrica. Y por ello son comparables. También, las provincias españolas tienen como equivalentes funcionales -aun con sus notorias diferencias- a las regional municipalities canadienses. Por lo demás, la comparación que sigue no se limita a exponer las similitudes y diferencias entre los dos sistemas locales, también ensaya algunas conclusiones comparativas o valorativas, sobre las ventajas o inconvenientes relativos de cada sistema.

Fijando la atención en la realidad normativa de cada sistema local, lo primero que hay que abordar es el tópico de que los países anglosajones -y esto incluye a Canadá- no conocen el Derecho administrativo o público como tal, como un ordenamiento diferenciado del common law. O que incluso no reconocen la distinción estructural entre Derecho privado y Derecho público. Hoy esto no es más que un tópico que no refleja la realidad, en general (Bardley y Ewing, 1993: 606; Auby, 2010; Cassese, 2010: 60; 140, Kischel, 2015: 345; Craig, 2016: 4), y desde luego la del régimen local canadiense. En Canadá, el Derecho local es fundamentalmente Derecho parlamentario (statutory law), mucho más que common law. Cada una de las provincias canadienses cuenta con un cuerpo legislativo muy extenso, y normalmente codificado, que regula con precisión todas las cuestiones del gobierno local. Y junto a ello, son numerosos los reglamentos gubernativos provinciales (regulations) en materias locales ${ }^{5}$, si bien estas posibles regulations gubernativas necesitan de

1 Este estudio ha recibido financiación del programa de investigación e innovación "Horizonte 2020", de la Unión Europea, conforme al Grant Ageement No. 823961 ("LoGov"). Agradezco a los colegas de la Western University de London (Canadá), y en especial al profesor Martin Horak, sus orientaciones para el correcto entendimiento del complejo sistema local canadiense. Ya en España, agradezco a César Martínez varias indicaciones sobre el sistema financiero español.

En este estudio, los textos normativos se citan según la forma propia de las distintas provincias canadienses. Así, los artículos de las leyes son sections (cuando se cita en inglés) y articles (cuando se cita en francés). Las leyes se citan siempre por las versiones consolidadas y codificadas; y se identifican por la manera que es usual en Canadá: sólo por su título completo y por el año (no por número de orden ni por la fecha completa). Las sentencias se citan conforme a los usos comunes en la práctica forense.

2 Sobre los contextos en la metodología comparada, recientemente: SCHMIDT-ASSMANN, E. (2018): "Zum Standort der Rechtsvergleichung im Verwaltungsrecht”, en Zeitschrift für ausländisches öffentliches Recht und Völkerrecht (ZaöRV), núm. 78, págs. 807-862 (pág. 850).

3 Por ejemplo: MASCARIN, J.; WILLIAMS, C. J. (2009): Ontario Municipal Act and Commentary. Toronto: Lexis Nexis Canada.

4 La metodología de la comparación horizontal, recientemente, en VELASCO CABALLERO, F. (2019): "Metodología comparada para el Derecho Administrativo", en Revista Española de Derecho Administrativo, núm. 200, págs. 51-79 (pág. 56).

5 Véase en este sentido, el listado completa de Regulations anejo a la versión actualizada de la Municipal Government Act de Alberta de 2000, Chapter M-26: http://www.qp.alberta.ca/documents/Acts/m26.pdf (págs. 3-9). 
autorización legal expresa («subject to regulatory activity...») minante para el conjunto del sistema local. Siguiendo la tradición británica, los tribunales de justicia (courts) cumplen una función secundaria en relación con la Administración pública. Así que la jurisprudencia sólo resulta propiamente relevante en relación con el alcance de los poderes municipales y con las liquidaciones tributarias.

\$4 Los gobiernos locales canadienses expresan la singular conjunción de varios vectores de cultura política y jurídica: la tradición política británica; la influencia de los Estados Unidos; y crecientes desarrollos institucionales endógenos.

a) La tradición política británica aún tiene mucho peso en Canadá. No hay que olvidar que Canadá es aún hoy una monarquía parlamentaria (su Jefa de Estado es la Reina Isabel II, del Reino Unido e Irlanda del Norte). La propia Constitución canadiense de 1867 (reafirmada mediante la Constitution Act de 1982) es, en puridad, una ley del Parlamento británico. Las raíces británicas del régimen local canadiense están presentes tanto en la diversidad de entidades locales (no hay un modelo local único o uniforme ni en el conjunto de Canadá ni en cada una de sus provincias) como en la tradicional consideración de las entidades locales -propia del common law- como private corporations, lo que aún hoy es relevante para determinar los poderes locales (infra § 28). Ello no obstante, los gobiernos locales canadienses no son hoy -como también es propio de la tradición británica (Wilson y Game, 2011: 57)- organizaciones instrumentales del Gobierno (en el caso de Canadá, de cada gobierno provincial). Más bien, el federalismo canadiense ha integrado por completo a las entidades locales en sus provincias, pero no las ha convertido en la Administración ordinaria de cada provincia. Son gobiernos propiamente locales -dedicados a asuntos locales- y no prioritariamente instrumentos político-administrativos de los gobiernos provinciales. Por eso, en importantes materias las entidades locales canadienses actúan en paralelo o de forma concurrente con departamentos y agencias de los gobiernos provinciales.

b) En segundo lugar, también son rastreables en el régimen local canadiense influencias o desarrollos paralelos a los de los Estados Unidos. Piénsese en los sistemas electorales municipales en Canadá (infra § 33). O en los diferentes niveles de autonomía local (home rule) de los que pueden gozar las distintas entidades locales. O piénsese también en el modelo de alcalde débil y de city manager, muy extendido en Canadá (infra § 42), y que originariamente fue introducido en los municipios norteamericanos a partir del vasto movimiento de reforma de mitad del siglo XX. Algunas de estas simetrías se deben a que Canadá comparte con Estados Unidos las raíces políticas británicas. Otras se deben a las notables similitudes políticas y demográficas de los dos países: ambos presentan un mismo tipo de federalismo, el anglosajón tradicional, que no considera a las entidades locales como un nivel de gobierno general (Young, 2009: 113); y también ambos países presentan una realidad demográfica y geográfica muy diversa, lo que bien puede explicar la gran diversidad y complejidad de las correspondientes plantas locales.

c) Amén de estas dos fuentes de influencia, los gobiernos locales en Canadá muestran crecientes desarrollos endógenos. Así, por ejemplo, en Québec se han ido introduciendo diversas reformas de descentralización infra-municipal (infra § 34) que no tienen parangón ni en Estados Unidos ni en el Reino Unido. También, los diversos ensayos de entidades metropolitanas de ámbito regional no tienen parangón ni en Estados Unidos ni el Reino Unido. Y por cierto, tampoco son influencia de Francia, que en general no es fuente de inspiración política ni legislativa (ni siquiera para Québec) desde principios del siglo XIX (Black, 2014: 164). Son, más bien, opciones políticas propias de las distintas provincias canadienses.

El sistema jurídico-local de Canadá presenta, en su conjunto, algunas diferencias estructurales con el régimen local español. Aunque ello no impide que los resultados prácticos de ambos sistemas sean comparables. De entrada, la Constitución canadiense, cuyo eje es la Constitutional Act de 1867 (ratificada en 1982) nada dice de los gobiernos locales, más que para someterlos a la jurisdicción de cada Estado federado (provincia). Y como tampoco hay propiamente constituciones provinciales, el sistema de gobierno local está confiado, por completo, a las leyes provinciales. Esto puede explicar los continuos cambios y vaivenes en el

6 Véanse por ejemplo, en materia financiera, las autorizaciones reglamentarias contenidas en la Section 271 Municipal Government Act 2000. 
REALA. Nueva Época - N.o 13, abril-septiembre 2020 - ISSN: 1989-8975 - DOI: 10.24965/reala.i13.10742 - [Págs. 22-46]

Gobiernos locales en Canadá y en España: lejos, pero no tanto

Francisco Velasco Caballero

sistema local de cada provincia. Pero no por eso, como luego se verá, las entidades locales canadienses son necesariamente menos autónomas que las españolas (infra § 22). Por lo demás, la estructura normativa del régimen local canadiense expresa una tensión estructural entre un cierto afán codificador y de estabilidad y una natural tendencia centrífuga, que da lugar a leyes especiales para municipios concretos o para corregir una concreta situación coyuntural no correctamente regulada en la legislación provincial general. De manera que las leyes generales de régimen local de cada provincia son objeto de desplazamientos y modificaciones continuas. Así, en lo que hace a las leyes especiales, una ley general como la Ontario Municipal Act de 2001, fue desplazada en la ciudad de Toronto (en 2006) por la City of Toronto Act, que a su vez dio lugar a múltiples modificaciones generales en la propia Ontario Municipal Act (Mascarin y Williams, 2009: 2).

Y ya una última precisión comparativa, de orden terminológico. Aunque en Canadá se usa la expresión Local Governments, tanto en el ámbito académico como en el normativo, está muy generalizado el término tradicional de municipalities (municipalités, en Québec). Este término comprende, en puridad, a toda clase de entidades locales, tanto a las territoriales (regiones, distritos metropolitanos, comarcas) como incluso a las instrumentales (police boards, school boards). Se distingue a veces entre general municipalities (las entidades locales territoriales) y las entidades instrumentales o special-purpose municipalities. Según esto, municipality es sinónimo de entidad local, no de municipio. Para hablar en Canadá de lo que en España se denomina propiamente «municipio» se utilizan allí los términos city, town o village (o ville, village, paroisse y canton) según el tamaño. Por sencillez expositiva, y para evitar cacofonías, en este texto se va a utilizar con frecuencia el sustantivo municipalities, dejando claro que ello incluye tanto a los municipios en sentido estricto como a las entidades locales supra o intermunicipales.

\section{SIMILITUDES Y DIFERENCIAS}

\$7 En muchos aspectos, los gobiernos locales canadienses presentan realidades, problemas y soluciones similares a los de las entidades locales españolas. Al igual que ocurre en España, en Canadá es patente la tensión política y jurídica entre las grandes ciudades y los gobiernos supralocales (en el caso de Canadá, las provincias). También como en España, los pequeños y medianos municipios son normalmente complementados con un segundo nivel local de gobierno local, comarcal o regional (infra § 12). En lo que hace a la actividad local, también hay alta coincidencia en los ámbitos de actuación local (los servicios básicos de vecindad) que normalmente no incluyen servicios sociales o sanitarios (infra § 25). Igualmente, en ambos países los gobiernos locales están dotados de cierta autonomía para la gestión de sus propios intereses (infra § 22). Internamente, el poder local se articula, tanto en Canadá como en España, en torno al alcalde y el consejo o pleno municipal (infra § 41). Incluso la financiación local es claramente comparable, con el acento puesto en el impuesto sobre la propiedad, que es complementado de diversas formas con transferencias supralocales (estatales, provinciales) y con otros impuestos y con tasas (infra § 44). Todo lo dicho sirve para trasladar la idea de que las entidades locales españolas y canadienses tienen importantes señas en común. Y esto es un punto de partida determinante para la comparación. Pues vista la existencia de notables similitudes, el estudio comparado debe centrarse en aquellas diferencias estructurales que pueden dar un sentido parcialmente distinto a realidades aparentemente simétricas. En este estudio, se van a señalar tres aspectos estructurales de los sistemas locales canadienses que enmarcan la comparación con el régimen local español. Hablo de: el federalismo; la diversidad organizativa; y las formas democráticas. Más adelante se irá viendo, en varios ámbitos materiales (planta local, forma de gobierno, competencias y controles, sistema electoral y financiación) por qué aquellos tres vectores estructurales son relevantes para la comparación.

\subsection{Federalismo}

El federalismo es una nota distintiva de Canadá. No es sólo un acuerdo constitucional (1867). Es la sustancia y realidad misma del país (Smith, 2010: 39). Son las diez provincias y los tres territorios de norte $-\mathrm{y}$ no las instituciones federales- quienes protagonizan el régimen local, tanto legislativa como administrativa y judicialmente. De acuerdo con esta caracterización general, el gobierno local es asunto exclusivo de cada provincia o territorio (Bish y Clemens, 2008: 11; Mascarin y Williams, 2009: 4; Díez, 2009: 219). Aunque la Constitución de Canadá (1867) apenas se refiere a las entidades locales, la única vez que lo hace es bajo la premisa implícita de que lo municipal es asunto de cada provincia (Section 92 [8] de la Constitución de 1867, mantenida en vigor por la Constitutional Act de 1982). 
El federalismo canadiense, a diferencia de los federalismos posteriores a la segunda guerra mundial, distribuye el poder público por entero entre el gobierno federal y las provincias. Esto es, sin reconocimiento constitucional alguno para las entidades locales. La Constitución canadiense de 1867 ni garantiza la autonomía de las entidades locales, ni impone ningún límite a las provincias a la hora de ordenar sus gobiernos locales. Se dice así, siguiendo un enunciado proveniente de la jurisprudencia norteamericana, que las municipalidades son «creatures of the province». En palabras de Tribunal Supremo de Canadá: «municipalities are entirely the creatures of provincial statutes. Accordingly, they can exercise only those powers which are explicitly conferred upon them by the provincial statute» ${ }^{7}$. Así que cada provincia o territorio regula con criterio propio sus gobiernos locales. Y también, cada provincia se reserva más o menos decisiones directas o controles - de legalidad o de oportunidad-sobre el funcionamiento de sus municipalidades. En términos comparativos son muy frecuentes en Canadá tanto las anexiones decididas por el gobierno provincial (un municipio incorpora una parte del territorio de otro) como las fusiones imperativas, expresamente previstas en algunas -no todas- las leyes provinciales ${ }^{8}$. El resultado es que los regímenes locales difieren considerablemente unos de otros, como también las condiciones geográficas y demográficas de las provincias divergen mucho entre sí. Aunque, como es propio del federalismo, también hay líneas de convergencia, normalmente por imitación. Así, la legislación de régimen local original de Alberta de 1994 (Alberta Municipal Government Act) ha inspirado la mayoría de las leyes municipales de las distintas provincias (Garcea y Lesage, 2008: 159; Díez, 2009: 243; Mascarin y Williams, 2009: 3). En todas ellas se contiene una visión expansiva del poder y la autonomía local. Esta convergencia de las leyes municipales ha permitido también la decantación de una jurisprudencia (tanto provincial como federal) que ya reiteradamente habla de una comprensión extensiva del poder municipal, como necesidad ante la complejidad actual de los asuntos locales (infra § 27). En términos muy generales, podrían agruparse los sistemas o regímenes locales en cuatro grandes grupos: el de la mayoría de las provincias, desde Ontario en el este, hasta British Columbia en el oeste, pasando por Manitoba, Saskatchewan y Alberta. Aun con diferencias, en todas estas provincias se observa una tendencia hacia un mayor reconocimiento institucional y de autonomía para el gobierno local. Un sistema peculiar es del de Québec, con un alto número relativo de entidades locales, estructuras locales algo arcaicas, y una neta distinción entre los municipios grandes y los pequeños (estos últimos, sometidos a un Code Municipal poco favorable a su autonomía). Las provincias marítimas (Newfound Land and Labrador, Nova Scotia, New Brunswick y Prince Edward Island), con sus diferencias, formarían otro grupo, donde la autonomía local se percibe algo más restringida. Y por último estarían los municipios de los tres «territorios», donde el gobierno local es muy singular, tanto porque aquí actúa directamente el gobierno federal como por la importancia de las comunidades aborígenes no integradas en gobiernos locales.

\subsection{Diversidad}

Ya se ha dicho que el federalismo genera, por sí, un alto nivel de diversidad en los gobiernos locales canadienses. Pero no es esté el único factor de diversidad local en Canadá. Cada provincia ejerce su competencia exclusiva sobre municipalidades para introducir numerosas regulaciones particulares, para concretas entidades locales o áreas geográficas específicas. Así que en un mismo tiempo y provincia coinciden distintos modelos y formas de gobierno local. De manera que, aunque todas las provincias y territorios cuentan con una regulación local general (las Municipal Acts), lo cierto es que o bien esas leyes permiten regímenes singulares para concretas ciudades o comarcas, o bien esas leyes generales no son aplicables en concretas ciudades, que cuentan con su propia ley de carta (es el caso de la Toronto Act 2006). Un buen ejemplo de la doble diversidad local canadiense, entre provincias y dentro de cada provincia, se encuentra en la valoración catastral (households assessment) para la determinación de la base imponible del impuesto municipal de propiedad (infra § 48). En algunas provincias la valoración catastral la realiza, para todos los municipios, un órgano provincial (por ejemplo, en British Columbia, la BC Assessment Authority). En otras provincias la valoración la realiza cada municipio. Y finalmente también es posible que en una misma provincia la valoración unas veces corresponda a la propia provincia y otras veces al municipio (como Winnipeg en Manitoba, o como Saaskatoon en Saskatchewan).

7 R. v Greenbaum [1993] S.C.J. No 24 [1993] 1 S.C.R. 674, 14 M.P.L.R (2d) 1, párrafo 22. La evolución de esta jurisprudencia, en DÍEZ SASTRE, S. (2009: 232).

8 Por ejemplo: Section 107 Alberta Municipal Government Act 2000. 
REALA. Nueva Época - N.o 13, abril-septiembre 2020 - ISSN: 1989-8975 - DOI: 10.24965/reala.i13.10742 - [Págs. 22-46]

Gobiernos locales en Canadá y en España: lejos, pero no tanto

Francisco Velasco Caballero

\subsection{Democracia}

Un tercer elemento diferencial de los gobiernos locales canadienses es la forma de la democracia local (Tindal y Tindal, 2008: 233). Más adelante se detallarán las distintas formas democráticas que coexisten en Canadá (infra § 32). Ahora, como elemento estructural de todo el sistema local, se llama la atención sobre el significado y formas del principio democrático. Aunque hay algunas excepciones notables -como Vancouver- la mayoría de los municipios canadienses tienen un sistema electoral mayoritario, con múltiples circunscripciones (wards) y normalmente con un único representante electo por circunscripción. En las mismas elecciones se suele elegir también al alcalde. Además, este sistema electoral actúa, normalmente, con ausencia de partidos propiamente dichos; al menos, tal y como los entendemos en España. La mayor excepción es el New Democratic Party (NDP), que sí presenta candidatos en diversos municipios. En todo caso, los candidatos lo son a título individual. Y no sólo en los municipios pequeños y medianos -como ocurre en los Estados Unidos- sino también en los grandes municipios. Ni los partidos políticos federales ni los provinciales verdaderamente cuentan en las elecciones municipales (Sancton, 2015: 178). Este sistema electoral es determinante para el conjunto del régimen local. En primer lugar, en lo que se refiere al sistema de gobierno local, las mayorías en el pleno son difíciles y complejas, porque no se articulan a través de los programas y las directrices de los partidos. Esto puede explicar la frecuente ausencia o retraso en la adopción de decisiones controvertidas (como grandes obras de infraestructura vial). La política municipal es, muy frecuentemente, más el resultado de equilibrios entre barrios o vecindarios que la ejecución de un proyecto integral de ciudad. En segundo lugar, la proximidad y coherencia entre el concejal electo y su distrito hace que la democracia local se articule mediante la interacción directa entre los vecinos y el concejal de cada distrito: tanto en la selección de los intereses objeto de defensa como para dar cuenta de la actividad representativa. Este modelo de interacción democrática activa y relativamente informal, que tiene su base en las circunscripciones electorales, se expande hacia el conjunto del ayuntamiento, donde se multiplican las consultas y audiencias ciudadanas (con frecuencia, con efectos paralizantes de las iniciativas políticas). Se puede hablar, en este sentido, de una democracia del día a día que condiciona todo el gobierno de la ciudad.

\section{LA PLANTA LOCAL}

La planta local de cada país se puede explicar por la singular conjunción en cada caso de varios elementos generales. Se cuentan aquí la estructura unitaria o federal del Estado, la demografía, el peso real del principio democrático, la tradición histórica y consideraciones de eficiencia económica (Velasco, 2013: 119). En puridad, en Canadá no se puede hablar de una «planta local». Hay tantas plantas locales como provincias. Y ni siquiera la planta local de cada provincia es uniforme, ni permanece estable a lo largo del tiempo.

a) En primer lugar, cada provincia canadiense es completamente autónoma para regular el tipo y forma de sus gobiernos locales. Así resulta, por ejemplo, que hay una gran diferencia entre el mapa local de British Columbia o Alberta, respecto de la planta local de Ontario o de Québec. Por ejemplo, Ontario, con casi el triple de población que Québec, tiene sólo una tercera parte de entidades locales (Garcea y Lesage, 2008: 163). Comparado con el régimen local español, es cierto que aquí las comunidades autónomas disponen de un cierto margen para la configuración de su propia planta local ${ }^{9}$. Y, de hecho, algunas comunidades autónomas han ejercido ese poder directamente a través de sus estatutos de autonomía ${ }^{10} \mathrm{o}$ a través de sus propias leyes de régimen local ${ }^{11}$. Pero es, salvo en el caso de los dos archipiélagos, un margen limitado. Porque la propia Constitución impone una planta local al

9 Arts. 151 y 84.3 del Estatuto de Cataluña (Ley Orgánica 6/2006, de 19 de julio, de reforma del Estatuto de Autonomía de Cataluña); art. 71.6. ${ }^{a}$ del Estatuto de Autonomía de Aragón (Ley Orgánica 5/2007, de 20 de abril, de reforma del Estatuto de Autonomía de Aragón); art. 70.1.4 del Estatuto castellano-leonés (Ley Orgánica 14/2007, de 30 de noviembre, de reforma del Estatuto de Autonomía de Castilla y León); art. 9.3 del Estatuto extremeño (Ley Orgánica 1/2011, de 28 de enero, de reforma del Estatuto de Autonomía de la Comunidad Autónoma de Extremadura); art. 105.1 del Estatuto Canario (Ley Orgánica 1/2018, de 5 de noviembre, de reforma del Estatuto de Autonomía de Canarias).

10 Así, art. 83.1 del Estatuto catalán; arts. 5 y 81 del Estatuto de Aragón; art. 43 del Estatuto castellano-leonés; art. 53 del Estatuto extremeño; art. 64 del Estatuto canario.

11 Ley castellano-leonesa 1/1991 de 14 de marzo, por la que se crea y regula la Comarca de El Bierzo; Decreto Legislativo aragonés 1/2006, de 27 de diciembre, por el que se aprueba el Texto Refundido de la Ley de Comarcalización de Aragón; Ley catalana 30/2010, de 3 de agosto, de Veguerías; Ley canaria 8/2015, de 1 de abril, de Cabildos Insulares. 
menos bimembre: municipios y provincias y/o islas en los archipiélagos canario y balear (arts. 137 y $141 \mathrm{CE}$ ). Esta planta local constitucional está luego desarrollada y formalizada como básica en la Ley 7/1985, de 2 de abril, reguladora de las Bases del Régimen Local (LBRL). A partir de esta planta local necesaria, cada Comunidad Autónoma puede añadir otras entidades locales (como las comarcas en Aragón o Cataluña, o como la comarca de El Bierzo en Castilla y León). También corresponde a cada Comunidad Autónoma definir la posible planta infralocal (en este caso con el límite del poder de autoorganización que corresponde a cada municipio). Pero esas posibilidades autonómicas son siempre complementarias o adicionales respecto de la planta local general.

b) En segundo lugar, al ejercer su competencia exclusiva sobre sus gobiernos locales, cada provincia canadiense diseña una estructura heterogénea de entidades locales para su propio territorio. No hay una planta local única para cada provincia, sino distintas estructuras municipales en función de las peculiaridades geográficas, económicas y demográficas de cada zona. Así, por ejemplo, la provincia de Québec cuanta con 1.131 municipios, de distintos tipos (villages, paroises, cités, cantons, villages nordiques). A algunos de estos municipios se superponen 87 entidades locales supramunicipales (municipalités régionales de comté [MRC] o, en el caso de Montréal y la ciudad de Québec, dos communautés métropolitaines); pero también hay un gobierno local de carácter regional (d'Eeyou Istchee Baie-James) y hay 12 municipios no integrados en ninguna entidad local comarcal o regional. En grandes líneas, cada provincia decide -muy condicionada por su estructura territorial y demográfica- si potencia la creación de grandes municipios, mediante anexiones y fusiones, o si mantiene la identidad de cada municipio preexistente, incluso en las áreas metropolitanas. Sumada a esta opción política, también es una opción provincial primaria si articula el gobierno local en cada zona o área en uno o dos niveles (tiers of government). Este apego de la estructura local a la realidad territorial ya indica de forma natural que la planta local de cada provincia no es estable. Los cambios políticos en cada provincia con frecuencia suponen cambios pequeños o grandes en la configuración de la planta local.

\$13 Con carácter general, en Canadá hay dos modelos de gobierno local: de un único nivel (single-tier) o de doble nivel (two-tier). Cada provincia decide dónde corresponde un gobierno local de nivel único o de doble nivel. No hay criterios únicos para determinar qué modelo de gobierno local procede en cada caso. En ocasiones hay municipios pequeños de nivel único (como el curioso municipio de Espagnola, en Ontario) aunque es frecuente que los municipios pequeños sean complementados con un segundo nivel de gobierno local de ámbito comarcal o regional (upper municipalities). Es el caso, en Québec, de las 87 municipalités régionales de comté (MRC) ${ }^{12}$. El gobierno local único (single-tier) puede ser tanto municipal como comarcal o regional. En la última década del siglo Xx varias provincias promovieron o impusieron la anexión o fusión de municipios para la formación de gobiernos locales únicos en las áreas metropolitanas y en otras áreas con población dispersa (Garcea y Lesage, 2008: 161). Este fenómeno, ampliamente criticado en entornos académicos y profesionales (Sancton, 2000; Slack y Bird, 2013: 29; Meloche y Vaillancourt, 2013: 8), no siempre ha producido los resultados esperados. De hecho, muchos de estos macro-gobiernos locales únicos no han sobrevivido. Significativo es el caso de Montréal, que en sólo cinco años pasó de anexionar todos los municipios de su entorno a segregar más de la mitad de esos municipios previamente anexionados (Meloche y Vaillancourt, 2013: 10).

\$14 Los municipios medianos o grandes tanto pueden tener un gobierno local único como depender también de un gobierno comarcal, regional o metropolitano. Es significativo, en el caso de Ontario, la existencia de varias «regiones» que se superponen a los gobiernos propiamente municipales de las ciudades grandes o intermedias alrededor de Toronto. También en Québec, sus dos grandes ciudades (Montréal y Québec) están integradas en sendas communautés métropolitaines. Lógicamente, la existencia de dos niveles de gobierno local (el municipal y el comarcal o regional) exige una cierta delimitación de competencias entre los $\operatorname{dos}^{13}$, y también alguna fórmula de participación en los rendimientos del impuesto sobre bienes inmuebles (property tax), que luego veremos que es la fuente fundamental de financiación local (infra § 44).

\$15 Hasta cierto punto, el modelo de doble nivel de gobierno local (municipal y comarcal o regional) se corresponde, en España, con la existencia simultánea de municipios y provincias. Aunque algunas diferencias

12 Esta información, actualizada a 2018, en: https://www.mamh.gouv.qc.ca/fileadmin/publications/organisation_municipale/organisation_territoriale/organisation_municipale_2018.pdf.

${ }_{13}$ En Québec, para las municipalités régionales de comté se distingue entre competencias exclusivas y competencias concurrentes: articles 101 a 126.5 Loi sur les compétences des municipalités du Québec 2005. 
REALA. Nueva Época - N.o 13, abril-septiembre 2020 - ISSN: 1989-8975 - DOI: 10.24965/reala.i13.10742 - [Págs. 22-46]

Gobiernos locales en Canadá y en España: lejos, pero no tanto

Francisco Velasco Caballero

estructurales son relevantes. De entrada, en España la provincia es de existencia necesaria (art. $141 \mathrm{CE}$ ), por lo que el gobierno local en su conjunto es tendencialmente de -al menos- dos niveles (el provincial y el municipal). La excepción estaría en las Comunidades Autónomas uniprovinciales, donde sólo hay un nivel imperativo de gobierno local (el municipal). Pues si bien es cierto que esas Comunidades Autónomas han asumido las competencias de las previas provincias, ejercen ya esas competencias no como entidades locales (y con legitimidad democrática local), sino como Comunidades Autónomas. En segundo lugar, la forma de las entidades locales de segundo grado en Canadá (upper municipalities) es muy diversa, no uniforme como en el caso de las provincias españolas. Depende de la propia estructura de cada territorio o zona dentro de cada provincia. Una última diferencia estructural está en que las entidades locales de segundo nivel en Canadá prestan servicios propios (recogida de residuos, alcantarillado, abastecimiento de agua, conservación de espacios naturales, etc.). Esto es, no se limitan a asistir, cooperar y coordinar técnica y económicamente a los municipios (como es propio y característico de las provincias españolas, conforme al art. 36 LBRL).

Una mención especial merece la planta local en las áreas metropolitanas canadienses. Con la excepción de las provincias atlánticas y los tres «territorios», lo normal en las demás provincias es que la población se concentre en ciudades grandes y en sus áreas metropolitanas. Por eso, el gobierno de las grandes áreas metropolitanas siempre ha sido un reto político, con más acuerdo en el diagnóstico de los problemas que en su solución (Graham y Phillips, 1998: 88). En general, las soluciones no han venido de la cooperación intermunicipal (convenios y mancomunidades). Más bien, las provincias han creado -con poco éxito en generalgobiernos locales específicos para las áreas metropolitanas (Garcea Lesage, 2008: 166). Bien mediante la fusión de la ciudad metropolitana y su entorno, bien mediante la creación de una nueva entidad metropolitana, superpuesta a cada uno de los municipios del área. Algunos de estos gobiernos metropolitanos tienen carácter general (para múltiples tareas) y otros son mono-funcionales. Con perspectiva temporal, algunos de los más importantes ensayos metropolitanos no han permanecido. Es el caso del Greater Toronto Services Board [GTSR] que apenas existió entre 1999 y 2001. De hecho, la gran área metropolitana de Toronto (Greater Golden Horseshoe) carece hoy de un gobierno unitario, aunque sí es una referencia geográfica para la planificación territorial de la provincia de Ontario $^{14}$. Otras organizaciones metropolitanas parecen más asentadas, como la autoridad de transporte del área metropolitana de Vancouver [Greater Vancouver Transit Authority: TransLink]) o como las Agglomerations de Montréal y Québec.

\$17 El número de municipios canadienses es, en su conjunto, relativamente alto. Son 5,162 municipalities generales o territoriales ${ }^{15}$. De ellas, la mayoría son municipios en sentido estricto (y no upper municipalities), aunque las estadísticas oficiales non ofrecen mayor detalle. En todo caso, el número de municipios es comparable al de España (8.123), si tenemos en cuenta que Canadá cuenta con casi diez millones de habitantes menos que España. Por otro lado, el alto número relativo de municipios, en ambos casos, indica que muchas de esas entidades son de pequeño o muy pequeño tamaño. En Canadá, los municipios pequeños se califican legalmente como villages (pueblos), por contraposición a las ciudades (towns or cities; y villes et cités, en Québec). Por ejemplo, son villages en British Columbia los municipios por debajo de los 2.500 habitantes. El alto número de municipios pequeños en los dos casos explica la existencia de gobiernos locales complementarios, de segundo nivel (comarcal, metropolitano o regional). Y bien, si hasta aquí las similitudes son claras, hay también algunas diferencias muy relevantes. En primer lugar, en Canadá son relativamente importantes los municipios de ámbito comarcal, que incluyen varios núcleos de población. Esta realidad contrasta con la tradición española, donde normalmente los municipios cuentan con un único núcleo de población (muchas veces, de muy reducidas dimensiones). En el caso de Canadá, la existencia de municipios comarcales hace a veces innecesaria la creación de entidades supramunicipales, como el distrito o la región (upper tier municipality).

\$18 Un rasgo llamativo del mapa local en Canadá consiste en que no todo el territorio del país forma parte de algún término municipal. Partes importantes del norte y centro del país («the prairie provinces») no forman parte de ningún municipio. Y se gestionan directamente por cada provincia. Aunque para la perspectiva europea esto pueda llamar la atención, es un dato cierto que incluso en una provincia con alta densidad relativa, como Ontario, sólo el $17,1 \%$ del territorio provincial forma parte de alguna entidad local, municipal o comarcal, si bien en ese territorio se concentra el $99,3 \%$ de la población provincial. Un caso bien distinto es el de las

14 "A Place to Grow Plan", aprobado por Order in Council No 641/2019 del Gobierno de Ontario y con vigencia desde el 16 de mayo de 2019.

15 Fuente: Statistics of Canada. Información vigente en 2017 conforme a los datos del censo de 2016. https://www12.statcan. gc.ca/census-recensement/index-eng.cfm. 
REALA. Nueva Época - N.o 13, abril-septiembre 2020 - ISSN: 1989-8975 - DOI: 10.24965/reala.i13.10742 - [Págs. 22-46]

Gobiernos locales en Canadá y en España: lejos, pero no tanto

Francisco Velasco Caballero

llamadas reservas indias (First Nations Governments), que no se incluyen en el mapa local ordinario (Bish y Clemens, 2008: 7 y 28; Díez, 2009: 229). Las reservas indias tienen su propio gobierno, diferente del propiamente local, aunque frecuentemente interactúan con los gobiernos locales de su entorno ${ }^{16}$ (normalmente para que los municipios les suministren, a cambio de precio, ciertos servicios indispensables como el suministro de agua). La realidad de territorios no integrados en municipios es, desde luego, extraña al régimen local español. Y se explica por la historia colonial de Canadá. De un lado, los municipios se han ido creando al compás de la expansión colonial desde el este del país. Y no se han creado por doquier, sino sólo donde se han generado asentamientos humanos que justificaban un nuevo municipio (incorporated municipality). Esto ha supuesto que tanto hacia el norte como hacia el interior del país, grandes áreas no plenamente colonizadas hayan quedado fuera del mapa municipal. La segunda exclusión territorial del área municipal -las reservas indias- se explica porque están reconocidas mediante tratados, no dependen de las leyes provinciales.

A diferencia de lo que ocurre en España, donde la planta local está muy asentada y las pocas variaciones resultan de segregaciones municipales, en las distintas provincias de Canadá hay un alto nivel de variación. A veces por segregación. Muchas otras veces por fusión (amalgamation), por incorporación de parte del territorio de otro municipio (annexation), o por simple creación de un municipio nuevo (incorporation) donde antes no había ningún tipo de gobierno local. Históricamente, esta alta mutabilidad del mapa local canadiense guarda estrecha conexión con la política territorial de cada provincia. Por épocas, y conforme a dogmas ideológicos e incluso académicos muy extendidos a finales del siglo $\mathrm{xX}$, algunas provincias han fomentado o directamente impuesto la fusión municipal, normalmente para mejorar la escala económica de gestión de los servicios municipales. Sin embargo, en los dos últimos decenios tanto las fusiones como las anexiones son muy limitadas. De un lado, las leyes provinciales muestran hoy mayor deferencia hacia los municipios existentes, limitando considerablemente las fusiones y anexiones imperativas. De otro lado, un importante sector académico y profesional cuestiona -con importante respaldo empírico- las supuestas economías de escala que resultan de las fusiones municipales (Bish y Clemens, 2008: 28). Además, se presta cada vez más atención a la pérdida de participación democrática asociada a la ampliación del tamaño de los municipios. El abierto cuestionamiento actual de las fusiones y anexiones municipales, en Canadá, contrasta con la extendida defensa académica de las fusiones en España (por todos: López Ramón, 2010: 80). Aunque también en España se ha puesto ha en duda, sobre todo desde el punto de vista económico, que las agregaciones municipales generen economías de escala. La propia lógica doméstica de gran parte de los servicios públicos locales, que se han de prestar allí donde efectivamente habitan los vecinos, hace que los costes de los servicios no se expliquen necesariamente por economías de escala, sino más bien por economías de densidad (Bel y Estruch, 2011: 193). Y la densidad no crece o disminuye por el mero hecho de la fusión o agregación. Haya uno o varios municipios, los núcleos de población son los mismos, y son estos los que determinan la estructura de costes de los servicios municipales.

Dentro del listado de gobiernos locales se incluye en Canadá tanto a las llamadas general-purpose municipalities (municipios, comarcas, distritos) como a las single-purpose municipalities: school boards, hospital districts, improvement districts, library districts, o police boards (por ejemplo: Bish y Clemens, 2008: 5). En esto el paralelismo con la realidad local de Estados Unidos es muy clara (véase: Briaffault y Reynolds, 2016: 13-16). Trabando comparaciones con España, las single-purpose municipalities podrían calificarse como organismos públicos locales. Aunque esta calificación comparativa es parcialmente imperfecta. Porque en el caso de Canadá las entidades de finalidad única (single-purpose) suelen presentar un nivel de autonomía (incluso financiera) muy considerable, en todo caso impropia de las entidades instrumentales en el régimen local español. El nivel de autonomía de estas entidades instrumentales en Canadá sería más parecido -guardando las distancias- al de las autoridades reguladoras independientes que actúan en España en el nivel estatal (Sánchez Morón, 2018: 227). Señas de la alta autonomía de aquellas entidades locales instrumentales canadienses son la frecuente elección democrática directa de los órganos rectores de esas entidades (como los school boards) o la dirección estrictamente profesional de otras de esas entidades (como los police boards), que no atienden a instrucciones o estrategias de los órganos políticos municipales. Decreciente es hoy el poder tributario de algunas entidades instrumentales (como los school boards) que tradicionalmente podían imponer un gravamen propio sobre la base imponible del impuesto sobre la propiedad inmobiliaria (Tindal y Tindal, 2008: 236; Sancton, 2015: 325).

16 Está colaboración está directamente prevista en, por ejemplo: Section 54(2) Alberta Municipal Government Act 2000; y article 14.8 Code Municipal du Québec 1916. 
REALA. Nueva Época - N.o 13, abril-septiembre 2020 - ISSN: 1989-8975 - DOI: 10.24965/reala.i13.10742 - [Págs. 22-46]

Gobiernos locales en Canadá y en España: lejos, pero no tanto

Francisco Velasco Caballero

\$21 De todo lo expuesto, el elemento más relevante para la comparación sería la relativa mayor rigidez de la planta local española, respecto de la canadiense. La rigidez española se observa tanto en la alta estabilidad de la planta municipal como en la necesaria existencia del doble nivel de gobierno local (municipal-provincial). Esta rigidez se explica, en parte, por el alto sentido de identidad territorial (en este caso, local) observable en España. Y en parte, también, por el propósito constitucional (y de la legislación estatal) de embridar el poder territorial de las Comunidades Autónomas. La rigidez normativa de la planta local ha impedido, en España, el efectivo desarrollo de una política territorial autonómica que adaptara la estructura local a las peculiaridades de cada comunidad o región. Así, la comarcalización en Aragón o en Cataluña ha sido muy limitada en sus resultados prácticos. Y aunque hay varias razones para este resultado, una muy importante es que el rígido esquema institucional municipio-provincia dificulta o directamente impide un sistema de gobierno local verdaderamente alternativo (y adecuado a cada territorio). La misma alta rigidez institucional está dando lugar a experimentos institucionales, como las mancomunidades integrales extremeñas (Ley extremeña 17/2010, de 22 de diciembre, de Mancomunidades y Entidades Locales Menores) o las mancomunidades comarcales valencianas (Ley valenciana 21/2018, de 16 de octubre, de Mancomunidades), que bien se pueden explicar por la rigidez y uniformidad de la planta local en España.

\section{AUTONOMÍA LOCAL: COMPETENCIAS Y CONTROLES}

\$22 Ya se ha dicho que el texto principal de la Constitución canadiense (1867) nada dice del gobierno local, más que para reconocer la entera competencia de cada provincia. Resulta, además, que las provincias canadienses no tienen constituciones propias (como si ocurre en otros Estados federales, como Estados Unidos o Alemania). Significa esto, en suma, que las leyes provinciales que regulan el régimen local no tienen ningún límite normativo expreso, salvo los que puedan derivar de los derechos fundamentales que desde 1982 incluye la Constitutional Act. Podría pensarse, en consecuencia, que a falta de garantías constitucionales expresas la autonomía local de las municipalities canadienses es comparativamente menor, o de peor calidad, que la que es propia de los municipios españoles. Así se ha entendido a veces en la doctrina canadiense, tomando como término de comparación la Carta Europea de la Autonomía Local de 1985 (Garcea y Lesage, 2008: 168). Esta conclusión no sería correcta. Las leyes provinciales canadienses, si bien no tienen claros límites constitucionales a la hora de regular el régimen local, reconocen importantes espacios de autonomía para sus municipalities. Tanto en lo que se refiere a las competencias como en lo que hace a su capacidad organizativa y financiera. Las más recientes leyes provinciales suelen hablar ya de sus municipalities como un «nivel de gobierno» (Bish y Clemens, 2008: 22) ${ }^{17}$ oponible al provincial y al federal. Por supuesto que en muchos ámbitos existen límites y supervisión provinciales. Es notorio que la planificación territorial de las provincias limita la autonomía urbanística municipal; y también es claro que las leyes provinciales autorizan a los correspondientes ministros de hacienda para dirigir y supervisar intensamente a las entidades locales de su territorio. Pero la autonomía local es real. Y en algunos ámbitos, muy destacable: fundamentalmente en aspectos de organización interna. O incluso para establecer el sistema electoral de cada municipio, donde cada pleno municipal cuenta con amplio margen de opción (infra § 33).

\$23 Al otro lado del océano, España sí garantiza constitucionalmente la autonomía local (art. 137 CE). Además, tanto la Carta Europea de la Autonomía Local (1985) como algunos Estatutos de Autonomía, reafirman esa autonomía. Mas esas garantías constitucionales, internacionales o estatutarias son poco exigentes. Y no impiden que las leyes -tanto estatales como autonómicas- ordenen y condicionen la autonomía local de forma simétrica a como lo hacen las leyes canadienses. Más aún: así como se observa que en Canadá la autonomía local es creciente en los últimos dos decenios (Díez, 2009: 219), justamente lo contrario se puede decir de España. Si en Canadá las leyes provinciales de régimen local -siguiendo el modelo de Alberta- han ido expandiendo la autonomía local, en España las distintas reformas legales desde 2003 (Ley 57/2003, de 16 de diciembre, de Medidas para la Modernización del Gobierno Local) y sobre todo la dramática reforma de 2013 (Ley de 27/2013, de 27 de diciembre, de Racionalización y Sostenibilidad de la Administración Local) han ido en sentido contrario: limitando progresivamente la autonomía local. En ello han participado también las Comunidades Autónomas, normalmente mediante leyes sectoriales que regulan con detalle la forma en la que los municipios han de ejercer sus competencias. El Tribunal Constitucional (al menos hasta la STC 41/2016) ha sido muy permisivo con estas limitaciones legales de la autonomía local.

17 Véase: Section 16 Ontario Municipal Act 2001. 
De los distintos indicadores con los que se puede medir la autonomía local (Rodríguez de Santiago, 2010: 525; Ladner et al., 2019: 37) aquí se va prestar atención a dos de ellos, las competencias y los controles. Otro muy relevante (la financiación) se tratará indirectamente en otra parte de este estudio (infra § 43).

\subsection{Competencias}

\$25 En lo que hace a las competencias, con una simple observación de la realidad local se constata que los municipios españoles y las municipalities canadienses desarrollan actividades muy similares. Esto incluye los clásicos servicios de vecindad (suministro de agua potable, alcantarillado, limpieza de calles y jardines, alumbrado público o policía local). Tendencialmente, los municipios españoles están más presentes en los servicios sociales (complementando a las Comunidades Autónomas), mientras que en Canadá -salvo en Ontario- los servicios sociales son una cuestión eminentemente provincial (Bish y Clemens, 2008: 4). En cambio, las municipalities canadienses ejercen más funciones en materia de enseñanza, normalmente a través de autoridades independientes (los school boards), si bien en el último decenio las provincias están desplazando a los gobiernos locales de esta tarea históricamente local. Como singularidad, los municipios canadienses despliegan tareas de gestión aeroportuaria y servicios de control y suministro energético (Bish y Clemens, 2008: 29) ${ }^{18}$, lo que en España es una actividad regulada por el Estado y prestada por entidades privadas en competencia.

\$26 Las actividades y servicios desarrollados por los municipios se fundamentan, tanto en Canadá como en España, en competencias expresamente atribuidas por las leyes. De dos formas: mediante listados sectoriales de competencias; y mediante alguna cláusula competencial general más o menos amplia. En Canadá, y partiendo de la tradicional comprensión de las entidades locales como creaciones o «criaturas» de cada provincia, se asumía pacíficamente que los gobiernos locales sólo podían actuar allí donde una ley provincial expresamente les confiriera autoridad o competencia. Por eso las leyes provinciales de régimen local tradicionalmente contienen un listado más o menos extenso de materias competenciales locales, la denominada «laundry list» (Mascarin y Williams, 2009: 8) ${ }^{19}$. Pero desde la década de los años 90 del siglo XX, el sistema ha ido evolucionando hacia una ampliación de las competencias locales (Garcea y Lesage, 2008: 168 y 178). En general, los gobiernos provinciales liberales han sido más favorables a la descentralización local que los conservadores (Garcea y Lesage, 2008: 169).

\$27 De un lado, varias leyes provinciales de régimen local incluyen hoy un mandato de interpretación amplia de las competencias locales ${ }^{20}$. Al hilo de esta regulación legal, los tribunales acogen en la actualidad una comprensión amplia de las competencias locales. Tal y como lo expresa el Tribunal Supremo de Canadá: «This court has often reiterated the social and political importance of local governments. It has stressed that their powers must be given a generous interpretation because their closeness to the members of the public who live or work on their territory make them more sensitive to the problems experienced by those individuals» (la cursiva es mía) ${ }^{21}$.

Una segunda forma de expansión funcional de los gobiernos locales canadienses consiste en la introducción de cláusulas competenciales generales. Reconocen hoy las leyes provinciales que las entidades locales pueden hacer todo aquello que corresponde a una «natural person», siempre que sea para conseguir el bienestar de los vecinos ${ }^{22}$. Esta referencia a los poderes de las «natural persons» reenvía tanto al common law como al statutory law que regula las sociedades de capital. Es una cláusula legal directamente emparentada con la que para Inglaterra (desde 2011) también incluye la Localism Act ("A local authority has power to do anything that individuals generally may do"). Aunque en su tenor literal la cláusula competencial general resulta amplia, también tiene límites. En primer lugar, la cláusula competencial general no incluye por sí aquellas potestades (powers) que no reconoce el common law, como el poder tributario o expropiatorio, por lo que tales poderes sólo se pueden ejercer en los casos y en la forma que especifican las leyes de régimen local. En segundo lugar, la competencia local general lógicamente se contrae a los asuntos de

18 En las leyes provinciales, véase: articles 14 a 18 Loi sur les compétences municipales du Québec; Section 303 (1) Nova Scotial Municipal Government Law 1998.

19 Véase hoy: Sections 10 y 11 Ontario Municipal Act 2001; y article 4 Loi sur les compétences municipales du Québec 2005.

20 Así: Section 8 (1) Ontario Municipal Act 2001; Section 9 Alberta Municipal Government Act 2000; Section 14 A) Nova Scotia Nova Municipal Government Act 1998.

21 Guinard v St-Hyacinthe (Ville), [2002] S.C.J. No 16, 27 M.P.L.R (3d) 1, párrafo 17.

22 Section 9 Ontario Municipal Act 2001; Section 6 Alberta Municipal Government Act 2000; article 85 Loi sur les compétences des municipalités du Québec 2005. 
interés local. Y aquí la jurisprudencia está acotando qué es y qué no es de interés local. Según el Tribunal Superior de Ontario, en un recurso contra la prohibición de comercialización de la aleta de tiburón establecida mediante ordenanza (bylaw) de la ciudad de Toronto: «In considering the breadth of the power of the City, it is important that the powers are delegated to the City [by the Toronto Act] to enable it to deal with "municipal issues", a term which is not defined. A by-law must have a proper municipal purpose; otherwise it falls outside the jurisdiction of the City and the powers delegated to it...» ${ }^{23}$.

Volviendo a la comparación, también el Derecho local español tiene, como el de las provincias canadienses, listados de competencias locales y algunas cláusulas generales de competencia. Pero no exactamente con el mismo alcance y efectos.

a) De entrada, las leyes españolas contienen tanto atribuciones competenciales sectoriales como deberes prestacionales (los servicios obligatorios del art. 26.1 LBRL, reproducidos también en leyes autonómicas, como el art. 67 del Decreto Legislativo catalán 2/2003, de 28 de abril, por el que se aprueba el Texto refundido de la Ley Municipal y de Régimen Local). La distinción no es irrelevante, y es un indicativo de menor autonomía política en los municipios españoles. En principio, siguiendo una consideración elemental e implícita en el régimen local canadiense, un gobierno local elegido democráticamente para el desarrollo de prioridades políticas propias necesita que la ley (statute) le atribuya competencias. Pero el ejercicio de esas competencias es -dentro de los límites de la leyuna decisión política de cada municipio. De ahí que resulte extravagante la idea misma de servicios públicos obligatorios. La falta de actividad del ayuntamiento, para servicios que le atribuye o permite la ley, será un problema de responsabilidad política del alcalde y los concejales ante los electores. Pero no la infracción de un deber legal. En España, en cambio, un legado del centralismo y de las recurrentes autocracias a lo largo del siglo xx es la fijación por ley de servicios municipales obligatorios. Con lo que son las leyes y los tribunales $-\mathrm{y}$ no los electores- quienes exigen el efectivo ejercicio de las competencias municipales.

b) Las competencias de los municipios españoles, atribuidas por las distintas leyes sectoriales estatales o autonómicas -en el marco del listado de materias del art. 25.2 CE y de los listados contenidos en algunos Estatutos de Autonomía- no se limitan a otorgar facultades. También regulan su ejercicio. Las leyes sectoriales españolas en materias competenciales locales son claramente prescriptivas. Regulan -con frecuencia con gran nivel de detalle- el ejercicio de las competencias que otorgan. $O$ remiten esa regulación a reglamentos estatales o autonómicos (no locales). Piénsese, por ejemplo, en la recogida y eliminación de los residuos sólidos, donde la Ley 22/2011, de 28 de julio, no se limita a enunciar las competencias municipales (art. 12.5), sino que también regula su ejercicio. La densa regulación legal, tanto estatal como autonómica, limita la existencia de políticas públicas propiamente locales en las materias de su competencia. $Y$ un buen indicador de ello es el escaso número relativo de ordenanzas municipales, consecuencia lógica de que todo lo jurídicamente relevante (como los derechos y deberes de los vecinos) está ya acabadamente regulado en normas de superior nivel. Por comparación, las leyes locales canadienses son normalmente más autorizatorias (enabling) que prescriptivas (Mascarin y Williams, 2009: 17). Es cierto que también en las leyes provinciales canadienses -tanto las de régimen local como las sectoriales- se encuentran algunos parámetros normativos sobre el ejercicio de las competencias que otorgan. Pero tales parámetros son normalmente muy selectivos y más imponen límites concretos a la actuación local que prescriben la concreta forma de actuación municipal ${ }^{24}$.

c) Lo dicho no es óbice para que, si bien las leyes no regulan en detalle el ejercicio de las competencias locales, diversos órganos gubernativos provinciales (tanto los ministros como diversos boards

23 Eng v Toronto (City), [2012] O.J. No 5661, 6 M.P.L.R (5 $\left.5^{\text {th }}\right) 1$ (S.C.J), párrafo 19. Véase también, en relación con la prohibición de las cachimbas en la ciudad de Toronto: 232169 Ontario Inc. (c.o.b. Farouz Shesa Café) v Toronto (City), [2017] O.J. No. 3042, 2017 ONCA 484 (CA).

24 Por ejemplo, cuando la Section 18 Alberta Municipal Government Act atribuye a las entidades locales poder sobre las carreteras locales, apenas si añade algunas precisiones y límites sobre el ejercicio de este poder (Ss. 22 y 23), pero no añade una regulación complementaria sobre el ejercicio de tal competencia. Igualmente, cuando el artículo 34 Loi de Cités et Villes (Québec) otorga a los municipios quebequeses competencias sobre eliminación de residuos, apenas si añade la posibilidad de gestión indirecta del servicio (si bien en todo caso la entidad local está vinculada -como cualquier otra persona productora o gestora de residuos- por la legislación general de medio ambiente y residuos de cada provincia). Y ya por último, la Section 325 Nova Scotia Municipal Government Act enuncia extensamente todas las políticas públicas que pueden desarrollar los municipios en materia de residuos sólidos, pero no regula ni estandariza el ejercicio de la competencia. 
sectoriales) sí ejerzan una amplia dirección gubernativa sobre las entidades locales. Así, por ejemplo, la Section 456 (1) Nova Scotia Municipal Government Act establece que «The Minister [provincial] may order a municipality to do anything required by law or by agreement with the Minister (...), or necessary or desirable in the interest of the municipalities...». Estas amplias facultades de dirección gubernativa supralocal son casi desconocidas en el régimen local español (infra § 30).

d) Menos diferencias sustanciales se pueden identificar, en cambio, en las cláusulas competenciales generales en Canadá y en España. En ninguno de los dos casos, y a diferencia por ejemplo de Alemania (art. 28 II de la Grundgesetz), existe una cláusula constitucional que atribuya a los gobiernos locales una competencia universal limitable por la ley (Velasco, 2009: 51; otra opinión: Carro, 1999-2000: 4851; Ortega, 2000: 39; García Roca, 2004: 23). En Canadá, como en España, las posibles cláusulas generales han de encontrarse necesariamente en la ley. En el caso de Canadá ya se ha visto que esas cláusulas hacen referencia al poder propio de cualquier «natural person». En el caso de España, el actual art. 7.4 LBRL actúa como una competencia municipal universal [STC 41/2016, FJ 10 d)] aunque somete el ejercicio de esa competencia a exigencias de sostenibilidad y «no duplicidad». Es cierto que las cláusulas competenciales generales de las leyes locales canadiense son bien distintas, en su forma normativa, a la competencia municipal general del art. 7.4 LBRL. Pero en la práctica, en ambos casos la competencia es tendencialmente amplia. En el caso de Canadá, porque el límite real de la competencia universal está en la existencia de «interés local» en la cuestión. Y en el caso de España, porque el doble control autonómico o estatal de «sostenibilidad y no duplicidad» ha sido de facto desactivado por la jurisprudencia constitucional y por las leyes autonómicas de desarrollo de la LBRL (Velasco, 2015: 35).

\subsection{Controles}

El segundo indicador de autonomía local, de los aquí considerados, es el de los controles supralocales. Podemos seguir, para guiar la exposición, la distinción tradicional y frecuente entre controles de oportunidad y controles de legalidad.

a) En Canadá son relativamente frecuentes los controles provinciales, sobre todo en materia urbanística y tributaria. Esos controles a veces se ejercen directamente por los ministros provinciales ${ }^{25}$. Aunque lo normal es que los controles se ejerzan por órganos provinciales independientes, siguiendo la tradición británica de los tribunals ${ }^{26}$. La misión principal, aunque no única de los tribunals es resolver las disputas entre los municipios y los particulares (entre ellas, las que tienen que ver con el planeamiento urbanístico y con las valoraciones catastrales). Esta labor no es el simple y estricto control de legalidad de decisiones municipales. Entre otras cosas, porque los parámetros de legalidad no siempre son precisos. Los tribunals pueden corregir las decisiones de las municipalities por razones de legalidad (law) y también con fundamentos de interés público (policy), a partir de una distinta valoración de los hechos ${ }^{27}$. Además de las apelaciones, los tribunales también realizan otras labores de control no litigioso sobre los municipios, sobre todo en materia financiera. En última instancia, y más allá de los recursos ante los tribunals, siempre existe el control de legalidad sensu stricto a través de los órganos judiciales provinciales (courts), con posible apelación ante el Tribunal Supremo de Canadá, si bien la vía judicial es relativamente inusual, entre otras razones por la amplia deferencia que los órganos judiciales conceden a las decisiones políticas locales (Díez, 2009: 247).

b) Bien distinto es el sistema de controles en España. Aquí, una temprana jurisprudencia del Tribunal Constitucional ${ }^{28}$ prohibió todo control de oportunidad sobre las entidades locales constitucionalizadas

25 Para Alberta, véanse los controles ministeriales regulados en las Sections 570 (1) 574 y 603 (1) Alberta Municipal Government Act 2000, que incluyen tanto las inspecciones ministeriales como la suspensión de decisiones municipales e incluso la aprobación sustitutoria y provisional de ordenanzas por el ministro. Para Nova Scotia, véanse los poderes ministeriales de aprobación previa de decisiones locales, incluidas las ordenanzas, en las Sections 79 D) y 450 Nova Scotia Nova Municipal Government Act 1998.

26 En relación con British Columbia: Bish y Clemens, 2008: 19. Para Ontario: Environment and Land Tribunals Ontario (ELTO), que sustituye desde 2018 al muy criticado (por sus amplios poderes) Ontario Municipal Board (https://elto.gov.on.ca). Para Québec, desde 1932: Commission Municipal (http://www.cmq.gouv.qc.ca). En Manitoba actúa, desde 2017, el Manitoba Municipal Board (https:// www.gov.mb.ca/municipalboard).

27 En relación con las valoraciones catastrales: Section 324 Alberta Municipal Government Act 2000.

28 STC 4/1981, FJ 3. Y luego: SSTC 27/1987, FJ 2 y 46/1992, FJ 2. 
(municipios, provincias e islas), y también toda suerte de control de legalidad sistemático que «situara a las entidades locales en una posición de sumisión cuasijerárquica». A estos límites constitucionales se han sumado otros límites impuestos por la legislación básica estatal (arts. 65 y ss. LBRL), que con carácter general prohíbe también cualquier control de legalidad sectorial que no esté expresamente previsto en una ley estatal. De manera que hoy en España sólo son constitucionalmente posibles los controles de legalidad específicos (sectoriales), y sólo cuando así lo prevea expresamente una ley estatal (como hacen, por ejemplo, los arts. 18 a 26 de la Ley Orgánica 2/2012, de 27 de abril, de Estabilidad Presupuestaria y Sostenibilidad Financiera).

\$31 Según se ve, el régimen de controles supralocales en Canadá, ejercido siempre por las provincias y nunca por el gobierno federal, es más amplio que en España. Y no se limita a controlar la legalidad de la actuación local. Poniendo en relación este dato con la menor densidad normativa de las leyes provinciales canadienses que regulan la actuación local, resulta que el mayor margen de opción política de las municipalities canadienses (por la menor densidad prescriptiva de sus leyes) se equilibra con un mayor control político o de oportunidad de la provincia (Díez, 2009: 228). Sería justo el envés del régimen local español, donde las leyes (y reglamentos gubernativos) dejan menor poder de opción política a los municipios, pero son muy escasos los controles gubernativos supramunicipales, tanto de legalidad como de oportunidad. Los controles, normalmente de legalidad, corresponden a la jurisdicción contencioso-administrativa.

\section{DEMOCRACIA}

§32 Los gobiernos locales, tanto en Canadá como en España, cuentan con legitimidad democrática. Pero las formas y alcance del principio democrático no son del todo coincidentes. Y estas diferencias son determinantes para todos los aspectos de la actividad local. De entrada, en los municipios canadienses apenas si están presentes los partidos políticos (Graham y Phillips, 1998: 105). Desde luego, los partidos políticos de ámbito nacional (como el partido liberal, el conservador, o el popular) no participan en los procesos políticos locales. Muy parecida es la situación con los partidos políticos provinciales. En ocasiones hay partidos políticos propiamente locales, pero lo normal es que la política local corra al margen de los partidos políticos. Sólo en Québec hay -y en todo caso de forma limitada- una mayor presencia de partidos políticos en el ámbito local.

§33 La situación descrita guarda estrecha relación con el propio sistema electoral, que normalmente lo decide cada entidad local, en el marco de opciones que ofrece la ley provincial de elecciones locales ${ }^{29}$. En la mayoría de los casos, y siguiendo la tradición británica, el sistema electoral es mayoritario y por circunscripciones múltiples (wards) en cada una de las cuales se elige uno o varios concejales (Sancton, 2015: 186). Son pocas las excepciones a este sistema. Sólo en British Columbia está extendida la elección mayoritaria en circunscripción municipal única. En el sistema electoral mayoritario por circunscripciones múltiples, y como ocurre también en los Estados Unidos, es determinante el número y la delimitación territorial de las circunscripciones. Por definición, en un sistema mayoritario las minorías de cada circunscripción no obtienen representación. Y si el mismo efecto se repite en muchas circunscripciones, puede darse el resultado final de que amplios sectores de la población municipal, por no ser mayoritarios en ninguna circunscripción, no obtienen ningún concejal en el pleno. Esto explica que en alguna ocasión los tribunals provinciales (supra § 30) hayan anulado delimitaciones de circunscripciones que de hecho impedían que determinados barrios y sectores sociales homogéneos pudieran elegir a su propio concejal ${ }^{30}$. No hace falta insistir en la importancia social y política que en Canadá se concede a la diversidad social. Y de ahí la importancia de que los grupos sociales homogéneos puedan obtener representación en un sistema electoral mayoritario con circunscripciones múltiples. Normalmente, en las mismas elecciones municipales en las que se eligen concejales se elige también directamente al alcalde o alcaldesa (en este caso, obviamente la circunscripción electoral es única).

29 Por ejemplo: Section 147 (2) Alberta Municipal Government Act 2000.

30 Es el caso de la delimitación de circunscripciones en Ottawa, que fue anulada por el Ontario Municipal Board (órgano provincial independiente) por medio de la decisión 0605, de 8 de marzo de 2003. Un relato completo del litigio y de la redefinición de las circunscripciones, en: https://app06.ottawa.ca/calendar/ottawa/citycouncil/csedc/2004/08-17/ACS2004-CRS-SEC-0037. Sobre la modificación de las circunscripciones de Toronto, véase la decisión del Ontario Municipal Board MM170033, de 15 de diciembre de 2017 (http://www.omb.gov.on.ca/e-decisions/mm170033-dec-15-2017.pdf). 
REALA. Nueva Época - N.o 13, abril-septiembre 2020 - ISSN: 1989-8975 - DOI: 10.24965/reala.i13.10742 - [Págs. 22-46]

Gobiernos locales en Canadá y en España: lejos, pero no tanto

Francisco Velasco Caballero

Es la regla por defecto en algunas leyes provinciales ${ }^{31}$, rara vez sustituida por la elección indirecta (esto es, por el pleno, de entre los concejales) en las ordenanzas electorales locales.

La democracia es algo más que las elecciones. Al margen de los procesos electorales, la participación ciudadana en los asuntos locales es muy considerable en Canadá. En forma de procedimientos participativos, comités ciudadanos y consultas (Graham y Phillips, 1998: 114; Bish y Clemens, 2008: 2). Es más, las reformas legislativas de los años 90 del siglo XX y primera decena de siglo XXI insistieron en la participación ciudadana, como también en la transparencia (Garcea y Lesage, 2008: 183). Incluso incentivaron la creación de distritos internos en las grandes ciudades (boroughs, arrondissements) como forma de participación de los vecindarios en el gobierno de la ciudad. Es el caso de Montréal, Toronto o Halifax (Garcea y Lesage, 2008: 165). Podría decirse que el aumento de autonomía local que contenían esas reformas legales (por el aumento de las competencias locales y por la reducción de los controles provinciales) se compensaba con controles democráticos difusos, mediante la transparencia y la participación ciudadana. Desde otra perspectiva, la permanente atención de los concejales electos a los vecinos de su circunscripción es coherente con dos factores políticos e institucionales ya señalados: la general ausencia de partidos políticos en el ámbito local y la general implantación de sistemas electorales mayoritarios -normalmente por circunscripciones de un solo candidato-. Estos factores estrechan la relación continua entre cada concejal electo y su vecindario o circunscripción.

§35 Lo descrito para los gobiernos locales canadienses claramente contrasta con la forma de la democracia local en España. Tanto en lo que hace al sistema electoral como en lo que se refiere a la participación ciudadana. En España, salvo en los municipios pequeños, los partidos monopolizan la vida política local. Los concejales independientes sólo fueron cuantitativamente relevantes en las primeras elecciones democráticas (1979), disminuyendo continuamente desde entonces (Navarro et al., 2019: 33). En directa relación con ello, el sistema electoral uniforme en España es de circunscripción municipal única; y proporcional corregido, mediante la fórmula D' Hondt (art. 205.3 de Ley Orgánica 5/1985, de 19 de junio, del Régimen Electoral General [LOREG]), excepto en los municipios muy pequeños, donde el sistema electoral es mayoritario (art. 184 LOREG). De otro lado, la participación local, aunque está claramente incentivada por la las leyes, tanto estatal (art. 69 LBRL) como autonómicas, también encuentra algunos límites legales considerables (para las consultas ciudadanas: art. 71 LBRL) y en la práctica cumplen una función secundaria.

§36 Las notorias diferencias en las formas democráticas entre España y Canadá permiten planear algunas valoraciones comparativas, en dos órdenes: en lo que se refiere a la calidad de la democracia local; y en lo que hace a la relación entre legitimidad democrática y la forma de gobierno local.

a) En términos comparados se podría pensar que la democracia local es más activa o intensa en Canadá que en España. La imagen social de los concejales canadienses en continua conexión con su electorado, sumada a la múltiple y real existencia de múltiples formas de participación ciudadana (más allá de las elecciones), parecerían avalar aquella conclusión. Pero hay algunos datos que la debilitan. De un lado, la participación electoral en los municipios canadienses es normalmente muy baja, rara vez por encima del $40 \%$ del censo (Graham y Phillips, 1998: 95; Kushner y Siegel, 2006: 264). Así, por ejemplo, en las últimas elecciones en Toronto (2018) la participación fue del $41 \%$ de censo electoral. Este dato contrasta con las elecciones en la ciudad española comparable (Madrid), donde en las elecciones locales de 2019 la participación fue del 67,6\% del electorado ${ }^{32}$. Con estos datos podría plantearse, para Canadá, si la intensa participación ciudadana está socialmente extendida o si sólo corresponde a ciertos grupos y sectores sociales minoritarios pero muy activos en la vida local (y a veces simplemente defensores de un concreto status quo, como son los movimientos locales NIMBY [not in my back yard]). Lo que sí parece una valoración comparada plausible es que la democracia local española es más electoral que participativa. Y que son los partidos -y no los ciudadanos o los vecindarios- quienes protagonizan la vida política. De otro lado, la democracia electoral en España dificulta la representación de las minorías ciudadanas y de los barrios o vecindarios. Estos sectores o grupos sociales, ni siquiera cuando están organizados, pueden competir electoralmente en un sistema proporcional de circunscripción única. En esto, como se ha visto, la democracia elec-

31 Así, Section 150 Alberta Municipal Government Act 2000; y para los counties también la Section 12 (8) Nova Scotia Nova Municipal Government Act 1998.

32 Para Toronto, véase la web oficial del municipio: https://open.toronto.ca/dataset/elections-voter-statistics/. Para Madrid se puede consultar la web oficial del Ministerio del Interior: https://resultados. elecciones/ocaleseuropeas19.es/\#/es/mun/resultados/provincias/madrid. 
toral canadiense es notoriamente más favorable a las minorías o los grupos sociales mayoritarios en concretos barrios, aunque minoritarios en el conjunto de la ciudad.

b) En principio, la forma de la democracia local en Canadá augura gobiernos débiles. Cada concejal se debe a su propia circunscripción. Y esto indica que las políticas de ciudad son el resultado de muy complejos acuerdos entre los diversos concejales y los intereses vecinales que representan (menos críticos: Graham y Phillips, 1998: 126). La inexistencia de partidos políticos locales agudiza esta situación, pues no existe una organización estable que de coherencia a los objetivos de cada concejal. Este resultado podría ser compensado -en hipótesis- reforzando las competencias del alcalde, frente a las del pleno. Pero como se verá en seguida, en la realidad local canadiense el alcalde es más un mediador o componedor de intereses (broker) que un órgano con poder público relevante. El contraste con la democracia local española es muy notorio. De un lado, el acceso de las minorías al pleno municipal es, como consecuencia del sistema electoral proporcional y la circunscripción única, muy limitado. Y sobre todo, los concejales no se deben a concretos vecindarios o grupos sociales, sino al conjunto de los electores y al partido que los presenta en sus listas. A esto hay que sumar la forma del gobierno local, que en España concede mucho poder directo al alcalde (arts. 21 y 124 LBRL) o a la junta de gobierno dependiente del alcalde (art. 127 LBRL). Todos estos factores políticos e institucionales conducen -normalmente- a gobiernos locales más fuertes, con más capacidad para reformas y decisiones estratégicas o de ciudad. Este resultado será muy claro cuando un partido obtenga una mayoría absoluta o muy clara en el pleno; y el gobierno local será algo más débil si el partido del alcalde no cuenta con esa mayoría en el pleno. Pero incluso en este último caso, las atribuciones legales propias de la alcaldía y la junta de gobierno (dependiente del alcalde) aseguran un amplio poder de decisión y liderazgo político en la ciudad (Navarro et al., 2019: 41). Lo dicho no cuestiona que en Canadá puedan existir gobiernos locales fuertes. Montréal es un buen ejemplo. Pero estos gobiernos locales resultan de sus concretos contextos sociales y políticos y de los liderazgos de algunos alcaldes carismáticos (Sancton, 2015: 232), más que del sistema político y de la forma de gobierno local.

\section{FORMA DE GOBIERNO}

\$37 Con la expresión «forma de gobierno» se hace referencia a cómo se distribuye el poder en el seno de las entidades locales. Esto es, cuáles son las atribuciones de cada órgano de gobierno. De entrada, hay que señalar que entre Canadá y España hay una diferente concepción sobre qué es gobierno (político) y qué administración ordinaria de la correspondiente entidad local. En Canadá los perfiles de ambas tareas están más marcados. En España, en cambio, la generalizada calificación de las entidades locales como Administraciones públicas (Parejo, 2004: 55) desdibuja las diferencias entre la política y la gestión local. Esta confusión, en España, se corrobora con la práctica: el alcalde, la junta de gobierno y los concejales (actuando por delegación de los dos anteriores) de hecho ejercen funciones típicamente administrativas y de gestión ordinaria de sus municipios. La figura del chief administrative officer (CAO), una suerte de directivo público profesional responsable de la gestión ordinaria del ayuntamiento, apenas si tiene real correspondencia en España. Sólo algunos municipios grandes o muy grandes, algunas diputaciones provinciales y algún cabildo insular cuentan con puestos próximos a los directivos públicos profesionales.

$\$ 38 \quad$ En una visión global de las distintas provincias canadienses, cuatro son las notas características destacables, en cuanto a la forma de gobierno: la amplia disponibilidad que tiene cada municipality para decidir la distribución interna de atribuciones; el generalizado protagonismo del pleno (council) y sus comités (committees); la posición secundaria del alcalde (mayor); y el protagonismo de los directivos públicos profesionales (chief administrative officers) en la gestión local. Veamos.

$\$ 39 \quad$ En primer lugar, la forma de gobierno local no está por completo impuesta por las leyes provinciales de régimen local. Con frecuencia, las leyes provinciales autorizan a los municipios para que -con ciertos límites- decidan mediante ordenanzas o reglamentos orgánicos (bylaws) su propia organización interna. Así, por ejemplo, la existencia de un órgano ejecutivo como la junta de gobierno (cabinet, comité executif) es una decisión local ${ }^{33}$. En general, este poder de autoorganización se percibe más limitado en la provincia

33 Articles 70.1 a 70.9 Loi sur les Cités et Villes du Québec 2005. 
REALA. Nueva Época - N.o 13, abril-septiembre 2020 - ISSN: 1989-8975 - DOI: 10.24965/reala.i13.10742 - [Págs. 22-46]

Gobiernos locales en Canadá y en España: lejos, pero no tanto

Francisco Velasco Caballero

de Québec (sobre todo en relación con los municipios pequeños ${ }^{34}$ ). Es frecuente que la ley provincial establezca una forma organizativa por defecto, modificable por ordenanza de cada municipality ${ }^{35}$. El contraste con el sistema de gobierno local en España es considerable. Aquí, el sistema de gobierno es muy uniforme, definido extensivamente en la legislación básica estatal (arts. 21 y 22 LBRL y, para los municipios de gran población, arts. 123 a 127 LBRL). El margen de opción tanto para las leyes autonómicas de régimen local como para los reglamentos orgánicos de cada entidad es muy limitado. Cuestión distinta es que mediante la práctica generalizada de las delegaciones, normalmente del alcalde en concejales (arts. 21.3 y 124.5 LBRL) o de la junta de gobierno en concejales (art. 127.2 LBRL) y más rara vez del pleno en la junta de gobierno (art. 22.4 LBRL), de hecho cada ayuntamiento relocaliza las atribuciones que la ley asigna al alcalde o al pleno municipal.

\$40 En segundo lugar, y tanto por decisión legal como por opción normativa de cada entidad local, en Canadá el pleno local ejerce la mayoría de las funciones decisorias (Sancton, 2015: 174 y 182) ${ }^{36}$. Y lo hace, normalmente, en forma de ordenanza. Dada la enorme magnitud de las atribuciones del pleno, lo normal es que éste actúe mediante comités sectoriales, permanentes o coyunturales, que deciden por delegación del pleno. En suma, el gobierno local canadiense es eminentemente corporativo. Lo cual guarda estrecha relación con la generalizada elección de los concejales por circunscripciones múltiples (supra § 33), lo que multiplica las legitimidades democráticas individuales y su necesaria concurrencia en la adopción de decisiones. Aquí también es notorio el contraste con el sistema de gobierno local en España, donde hay un mayor equilibrio de poder entre el pleno local, de un lado, y el alcalde o la junta de gobierno, del otro lado. Por supuesto que en España las decisiones políticas más trascendentes o estratégicas están reservadas al pleno. Pero, como demuestran las recientes experiencias de alcaldes y alcaldesas en minoría, en España es posible el gobierno local con la oposición mayoritaria del pleno (Navarro et al., 2019: 42), lo que es inimaginable en Canadá.

Aunque hay varios modelos de alcaldías, en cada provincia y dentro de cada provincia canadiense, en términos generales los alcaldes y las alcaldesas (son pocas estas, por cierto) prácticamente carecen de poder público formal (Sancton, 2015: 229), de atribuciones decisorias concretas distintas de la dirección política general y la fijación del orden del día del pleno ${ }^{37}$. El mayor, head of council o chief elected officer, como se le denomina en algunas provincias, es más un mediador entre intereses contrapuestos (broker) que un cargo con poder decisorio. Las leyes provinciales que siguen el modelo de Alberta permiten a las municipalities aumentar el poder decisorio del alcalde, restringiendo el del pleno ${ }^{38}$, aunque de hecho son pocas las entidades locales (algunas muy importantes, como Toronto, Montréal o Winnipeg) en las que el pleno opta por perder poderes frente al alcalde. Bien diferente es la alcaldía en el régimen local español. Desde la perspectiva canadiense podría decirse que la forma de gobierno local en España es claramente presidencialista. En los municipios españoles de régimen común, el alcalde cuenta con numerosas atribuciones propias, tanto de carácter político como administrativas o resolutivas (art. 21.1 LBRL). Y en los municipios de gran población, aunque la alcaldía pierde competencias decisorias y ejerce una función de liderazgo político (art. 124.4 LBRL), lo cierto es que la pérdida de competencias decisorias no es en favor del pleno, sino de la junta de gobierno local, que preside el alcalde y en la que nombra discrecionalmente a todos sus miembros. Con lo que, en última instancia, también en los municipios de gran población hay una distribución equilibrada de poder entre el alcalde (con la junta de gobierno) y el pleno municipal.

$\$ 42$ Finalmente, en Canadá la gestión ordinaria de cada municipality está relativamente separada de los órganos políticos (council \& mayor). Mucho más en los municipios grandes que en los pequeños (Garcea y Lesage, 2008: 180). Es clave en este sentido la figura del city manager o chief administrative officer, derivado del movimiento de reforma local en los Estados Unidos y que ha encontrado buena acogida en Canadá. Incluso se ha impuesto legalmente en algunas provincias como Québec (aunque sólo para las grandes ciudades, no para los demás municipios ${ }^{39}$ ), las «provincias de la pradera» (Manitoba, Saskatchewan, Alberta ${ }^{40}$ )

34 Cfr.: articles 79-108, 143-164, 445-454 Code Municipal du Québec 1916; articles 318 a 333 y 340 a 368 Loi sur les Cités et Villes du Québec 2005.

35 Así: Sections 143-146 Alberta Municipal Government Act 2000.

36 Cfr.: Section 5 (1) Ontario Municipal Act 2001; article 83 Code Municipal du Québec 1916; article 47 Loi sur les Cités et Villes 2005; y Section 14 Nova Scotia Municipal Government Act 1998.

37 Cfr.: Section 154 Alberta Municipal Government Act 2000 y Section 226.1 Ontario Municipal Act 2001; article 52 Loi sur les Cités et Villes du Québec 2005.

38 Así: Section 202 (2) Alberta Municipal Government Act 2000.

39 Cfr.: article 112 Loi sur les Cités et Villes du Québec 2005 y articles 210 y 211 Code Municipal du Québec 1916.

40 Section 205 (1) Alberta Municipal Government Act 2000. 
REALA. Nueva Época - N.o 13, abril-septiembre 2020 - ISSN: 1989-8975 - DOI: 10.24965/reala.i13.10742 - [Págs. 22-46]

Gobiernos locales en Canadá y en España: lejos, pero no tanto

Francisco Velasco Caballero

y Nova Scotia (aunque sólo para sus regional municipalities ${ }^{41}$ ). El city manager, que es un puesto directivo profesional y no un cargo electo, dirige al conjunto de la administración y los empleados locales. Según esto, no son ni el council, ni sus múltiples committees, como tampoco los concejales o councillors quienes directamente o por delegación -como en España- gestionan cada localidad. Los órganos políticos hacen policy, no administration. Lo expresa muy bien la Section 30 (4) de la Nova Scotia Municipal Government Act cuando establece que ningún concejal puede dar instrucciones a los empleados municipales, pues esta es una función reservada al city manager. Aquí el contraste con el régimen local español no puede ser más claro. El directivo público profesional es un puesto institucional que, aunque esté previsto en el art. 13 EBEP, no ha tenido un desarrollo apreciable (Jiménez Asensio, 2009: 60). Con algunas excepciones notables, la administración ordinaria de las entidades locales no se dirige por directivos profesionales, sino por concejales delegados, con la menor o mayor colaboración de funcionarios con habilitación nacional (secretarios, interventores, tesoreros). Esto explica también la alta profesionalización relativa de los concejales, incluso en los municipios pequeños y medianos. Y aunque en Canadá también es frecuente la profesionalización de los concejales, es un fenómeno más restringido a las grandes ciudades (Sancton, 2015: 270).

\section{FINANCIACIÓN}

§43 En términos contables, las haciendas locales, tanto en Canadá como en España, están saneadas. Esta afirmación puede parecer paradójica si tenemos en cuenta las reiteradas quejas sobre financiación de los representantes políticos locales (tanto en Canadá como en España) y que algunas necesidades financieras (por la mayor demanda de servicios locales cada vez más costosos y por las necesidad de renovación de infraestructuras que han devenido rápidamente obsoletas) no vienen acompañadas de un aumento correlativo de los ingresos. Por eso hay que precisar que el buen estado de la hacienda local se refiere al balance contable de activos y pasivos (assets and liabilities) o al equilibrio de ingresos y gastos presupuestarios (revenues and expenditures). Pero esto tiene más que ver con los límites legales al endeudamiento y al déficit presupuestario que con la necesidad real de mejora de la financiación, que es un problema real tanto en Canadá como en España.

\$44 Es una constante casi universal que los gobiernos locales se financian por tres vías principales: impuestos propios; transferencias centrales o regionales; y tasas o precios por la prestación de servicios públicos. A estas tres fuentes principales de financiación se suman otras normalmente menores, como el crédito público o privado, operaciones o ingresos por patrimonio propio, contribuciones de promociones urbanísticas, o el producto de las sanciones pecuniarias. Lo que cambia de país a país no es tanto la tipología de las fuentes de ingresos como la relevancia de cada una de esas fuentes en el presupuesto local. El esquema general expuesto es, en lo que sigue, la base para la comparación de la financiación local en Canadá y en España. Recordando de nuevo, eso sí, que en España el sistema financiero local es prácticamente uniforme (regulado en la Ley de Haciendas Locales) y en Canadá se regula por completo por cada provincia (con frecuencia, en la correspondiente ley general de municipios o gobiernos locales). En el cuadro que sigue se cifran, con información estadística correspondiente a 2017 (para Canadá) y a 2016 (para España), y una vez homogeneizadas las correspondientes categorías, los rendimientos de cada fuente de ingresos ${ }^{42}$. Para Canadá se han seleccionado los datos referidos a sólo tres provincias, las más pobladas (Ontario, British Columbia y Québec).

\section{TABLA 1. CANAdÁ}

\begin{tabular}{|c|c|c|c|}
\hline $\begin{array}{l}\text { Ingresos (excluidos los provenientes de créditos } \\
\text { y de subvenciones finalistas) }\end{array}$ & ONTARIO & $\begin{array}{l}\text { BRITISH } \\
\text { COLUMBIA }\end{array}$ & QUÉBEC \\
\hline Impuestos propios (\% del total de ingresos) & 47 & 56,7 & 64,3 \\
\hline Impuesto de propiedad & $(42)$ & $(46,6)$ & $(62,6)$ \\
\hline Impuesto sobre bienes y servicios & $(7)$ & $(10,1)$ & $(1,7)$ \\
\hline
\end{tabular}


REALA. Nueva Época - N.o 13, abril-septiembre 2020 - ISSN: 1989-8975 - DOI: 10.24965/reala.113.10742 - [Págs. 22-46]

\begin{tabular}{lccc}
\hline $\begin{array}{l}\text { Ingresos (excluidos los provenientes de créditos } \\
\text { y de subvenciones finalistas) }\end{array}$ & $\begin{array}{c}\text { BRITISH } \\
\text { COLUMBIA }\end{array}$ & QUÉBEC \\
\hline Tasas y cargas (\% del total de ingresos) & 20,8 & 34 & 17,8 \\
\hline Transferencias (generalmente provinciales) (\% del total de ingresos) & $22,2^{*}$ & 5,8 & 13,6 \\
\hline Otros (\% del total de ingresos) & 3 & 3,5 & 4,3 \\
\hline
\end{tabular}

* La elevada cifra de transferencias provinciales a las entidades locales de Ontario se explica porque en esta provincia, a diferencia de todas las demás, la sanidad y los servicios sociales se gestionan en buena medida por los municipios o entidades locales comarcales, y se financian precisamente mediante transferencias provinciales (SANCTON, A. Canadian Local Governments. An Urban Perspective, cit., pág. 295).

TABLA 2. EsPAÑA

\begin{tabular}{lc}
\hline \multicolumn{2}{c}{ Ingresos (excluidos los provenientes de créditos y de subvenciones finalistas) } \\
\hline Impuestos propios (\% del total de ingresos) & 45,5 \\
\hline Impuesto sobre bienes inmuebles (IBI) & $(27,9)$ \\
\hline Impuesto sobre vehículos de tracción mecánica (IVTM) & $(4,8)$ \\
\hline Impuesto de actividades económicas (IAE) & $(3,0)$ \\
\hline Impuesto sobre construcciones, instalaciones y obras (ICIO) & $(1,4)$ \\
\hline Impuesto sobre el Incremento de Valor de los Terrenos de Naturaleza Urbana (IIVTNU) & $(5,6)$ \\
\hline Otros & $(2,8)$ \\
\hline Tasas (\% del total de ingresos) & 16 \\
\hline Transferencias (fundamentalmente del Estado) (\% del total de ingresos) & 34 \\
\hline Otros (\% del total de ingresos) & 4,5 \\
\hline
\end{tabular}

Tal y como se aprecia en el cuadro anterior, en Canadá son los impuestos propios, y en especial el impuesto sobre bienes inmuebles (property tax, taxe foncière), la mayor fuente de ingresos en los presupuestos locales. Luego siguen las tasas por la prestación de servicios locales. Y el tercer puesto corresponde a las transferencias (normalmente provinciales). En España también los impuestos, y en especial el impuesto de bienes inmuebles (IBI), es la primera fuente de ingresos municipales, aunque con magnitudes inferiores a las de Canadá. Luego, a diferencia de Canadá, siguen las transferencias (normalmente estatales) y el tercer puesto es para las tasas. Una importante diferencia comparativa es que el sistema de financiación descrito rige en Canadá para todas las entidades locales (tanto municipios como comarcas, regiones o distritos metropolitanos), mientras que en España es bien distinta la financiación de los ayuntamientos, que se articula a través de las tres fuentes de ingresos mencionadas, y la de las entidades locales supramunicipales (provincias y, donde existen, comarcas), que se financian casi en exclusiva a través de transferencias, estatales o autonómicas.

La medida en que un sistema financiero descansa sobre cada fuente de ingresos no es neutra, ni casual. La financiación municipal a través de impuestos propios potencia la eficiencia y la responsabilidad democrática en las decisiones políticas sobre gasto, porque la misma entidad que aprueba el gasto debe trasladar su coste a los ciudadanos. Pero un peso excesivo de la financiación impositiva puede generar graves desigualdades y la expulsión o «guetización» de la población con rentas bajas. Las transferencias estatales o regionales tienen una clara función compensatoria, porque las reciben (al menos) los municipios con menos recursos propios. Pero aportan poca responsabilidad en el gasto: las decisiones locales no miran a los costes, porque no los repercuten de forma inmediata sobre los vecinos del municipio. Finalmente, las tasas pueden resultar justas, porque se vinculan directamente al beneficio que obtiene quien las paga; y son eficientes, porque atemperan la demanda de servicios municipales (Duff, 2004: 391; Martínez, 2014: 52-63). Pero las tasas también pueden generar problemas de igualdad e incluso de exclusión, para aquella 
REALA. Nueva Época - N.o 13, abril-septiembre 2020 - ISSN: 1989-8975 - DOI: 10.24965/reala.i13.10742 - [Págs. 22-46]

Gobiernos locales en Canadá y en España: lejos, pero no tanto

Francisco Velasco Caballero

población con poca renta y que ha de pagar por todo tipo de servicios locales. Según esto, y como guía para comparar los sistemas financieros locales en Canadá y en España, se podría considerar que un modelo óptimo es aquel que se nutre de forma equilibrada de estas tres formas básicas de financiación, en función del tipo de municipio (rural o urbano, con mayor o menor actividad económica) y de las actividades y servicios desarrollados por cada entidad local (Kitchen y Slack, 2016: 4). Así se asegura -al menos en parte-el efecto positivo de cada tipo de ingreso, y al tiempo se evita que el protagonismo excesivo de alguna fuente de ingresos genere efectos regresivos indeseables.

En lo que hace específicamente a la financiación con impuestos propios, hay una clara simetría inicial entre la financiación municipal canadiense y la española, pues en ambos casos son los impuestos propios la mayor fuente de ingresos. Sentado esto, la mayor diferencia en la financiación por vía de impuestos está en el mayor o menor protagonismo del impuesto sobre la propiedad (IBI vs property tax). Y aquí claramente se observa que el property tax es prácticamente el único impuesto local con capacidad recaudatoria efectiva. Con frecuencia, las leyes provinciales sólo autorizan este impuesto municipal. Y aunque a veces enuncien un poder impositivo general a favor de los municipios, seguidamente prohíben un largo listado de hechos imponibles, lo que en la práctica equivale a autorizar sólo el property tax ${ }^{43}$. Aunque las cifras varían de forma relevante en las distintas provincias, en todo caso se observa la altísima dependencia de las entidades locales canadienses respecto del property tax. Esta dependencia es frecuentemente cuestionada en ámbitos académicos (Kitchen y Slack, 2016: 7; una excepción: McMillan y Dahlby, 2014: 26). De un lado, por las propias limitaciones y externalidades inherentes a un impuesto sobre la propiedad inmueble (infra § 50); y de otro lado porque la concentración de la carga tributaria en un único impuesto (el property tax) dificulta la consideración de las diversas situaciones de capacidad contributiva, más allá de la titularidad de bienes inmuebles. En este punto ya se está experimentando en Canadá -teniendo en cuenta referencias comparadas que incluyen a España- una mayor diversidad de impuestos municipales. Por ejemplo, sobre la circulación de vehículos en las ciudades, o sobre las pernoctaciones hoteleras. Estas experiencias aproximan a Canadá al actual sistema de impuestos municipales en España, donde el IBI es sin duda la mayor fuente de ingresos tributarios, pero donde también hay aportaciones de otros impuestos: sobre los vehículos de tracción mecánica (IVTM); sobre el incremento del valor de los terrenos urbanos (IIVTNU); sobre las actividades económicas (IAE) o sobre las obras e instalaciones (ICIO). Y si bien es cierto que el rendimiento de cada uno de estos tributos municipales españoles es relativamente bajo (en comparación con la capacidad recaudatoria del IBI), también es cierto que de forma agregada son una importante fuente de ingresos sobre todo en fases álgidas del ciclo económi$\mathrm{co}$, porque descansan sobre hechos imponibles que guardan directa relación con el aumento de la actividad económica (a diferencia del IBI, que grava de forma estable el valor catastral de los inmuebles). Igualmente, para reducir la relevancia global del property tax se ha propuesto en Canadá -al menos para las grandes ciudades- un gravamen local complementario sobre la renta y las ventas, gravamen asociado (piggybacked) y sobre la misma base imponible de los correspondientes impuestos federales o provinciales (income tax y sales tax) (Sancton, 2015: 327; Kitchen y Slack, 2018: 8). Esto es parcialmente distinto de la simple cesión a algunos municipios de los rendimientos de algunos tributos estatales (arts. 111 a $117 \mathrm{LHL}$ ) o de la participación de todos los municipios en los rendimientos de tributos estatales (arts. 118 a 126 LHL).

\$48 En lo que hace específicamente a la estructura normativa del property tax, las similitudes con el IBI son considerables. En ambos casos la base imponible resulta de una previa valoración (assessment) de cada inmueble (household). Sobre esa base imponible cada municipio (o también cada entidad local supramunicipal, en el caso de Canadá) fija un tipo impositivo. Además, lo normal es que la valoración catastral no la haga la propia entidad local. En el caso de España, la valoración corresponde en exclusiva al Catastro (art. 65 LHL), y en Canadá suele corresponder a un órgano independiente provincial, aunque las leyes de algunas provincias autorizan a ciertas ciudades para hacer su propia valoración catastral (Sancton, 2015: 318 44. $^{4}$

\$49 Aunque el tipo impositivo es una decisión política del pleno municipal (council), en Canadá existe una práctica presupuestaria constante según la cual el tipo de impositivo se calcula de forma mecánica, en función de la cifra total del gasto presupuestado que no se cubre con otras fuentes de ingresos presupuestadas (tasas y transferencias provinciales, fundamentalmente). La simple división del total de gasto presupuestado pendiente entre el valor catastral agregado de todos los inmuebles de cada municipio determinaría el tipo

43 Por ejemplo, para los municipios pequeños y medianos de Québec: article 1000.1 Code Municipal du Québec 1916; y para las ciudades y villas: articles 486 y 500 Loi sur les Cités et Villes du Québec 2005.

44 En ocasiones se autoriza a los ayuntamientos a hacer sólo la valoración referida a los inmuebles residenciales, pero no a los industriales (Section 302 Alberta Municipal Government Act 2000). 
REALA. Nueva Época - N.o 13, abril-septiembre 2020 - ISSN: 1989-8975 - DOI: 10.24965/reala.i13.10742 - [Págs. 22-46]

Gobiernos locales en Canadá y en España: lejos, pero no tanto

Francisco Velasco Caballero

impositivo en cada ejercicio presupuestario. Está práctica pone en directa relación la carga impositiva local (a través del property tax) con el gasto municipal, lo cual es muy valorable en términos de responsabilidad en el gasto local (accountability), aunque presenta como objeción que hace la actividad local muy dependiente de las decisiones tributarias (y con ello, de las movimientos políticos antitributarios muy presentes en Canadá, al igual que en los Estados Unidos). En términos generales, y dado el protagonismo del property tax en los municipios canadienses, el tipo de gravamen es sensiblemente más elevado en Canadá que en España. Así, si los municipios españoles tienen tipos generales IBI en torno al 0,50\% de la base imponible (que además se actualiza con considerable demora, por lo que por regla general el valor catastral no se corresponde exactamente con el valor real), en Canadá el tipo impositivo está más bien en torno al $1,5 \%$ y en las grandes ciudades -excepto Vancouver- es incluso más alto (1,9\% en Toronto, 1,9 en Montréal, 2,47\% en Mississauga), tipos estos que incluyen el tramo de gravamen directamente destinado a la financiación de las escuelas.

El alto valor del property tax en las ciudades canadienses explica el enorme protagonismo político de este impuesto en la vida política de las ciudades canadienses. De un lado, la característica expansión urbanística horizontal de las ciudades canadienses (urban sprawl) tiene mucho que ver con el interés municipal en generar nuevas bases imponibles para el property tax (Tindal y Tindal, 2008: 222). De otro lado, con frecuencia las decisiones privadas sobre adquisición de inmuebles incluyen como un factor relevante la cuantía del property tax anual que corresponde al inmueble. Además, el protagonismo impositivo del property tax es causa de que grandes sectores de pensionistas o simplemente ancianos con pocos ingresos actuales (aunque dueños de inmuebles de alto valor catastral) se vean incapaces de pagar el impuesto de propiedad (Kitchen y Slack, 2016: 7) y opten por el cambio de residencia, lo que es abiertamente contrario a lo que patrocinan las políticas locales de friendly aging (Velasco, 2018: 3). También está el problema de la población flotante de las grandes ciudades (commuters) que consume bienes y servicios públicos locales donde trabaja o donde localiza su ocio o compras, pero que no está sujeta al property tax de esa ciudad. En todo caso, todos estos problemas que atañen al property tax no cuestionan tanto su existencia misma (difícilmente planteable) como su excesivo peso relativo, teniendo en cuenta que: grava un bien, la propiedad inmobiliaria, que no siempre es expresión de alto poder adquisitivo; sólo grava a los propietarios pero no a otras personas que se benefician de los servicios locales; y que es relativamente inelástico, pues no guarda relación necesaria con la actividad económica (Kitchen y Slack, 2016: 7).

En el cuadro comparativo de ingresos (supra § 44) también destaca comparativamente el mayor peso que en Canadá tienen las tasas o precios por la prestación de servicios públicos locales. Esta mayor relevancia de las tasas canadienses en los ingresos locales es, además, creciente. Esto resulta, en parte, de consideraciones de eficiencia económica y justicia fiscal: que nadie pague por los llamados private goods o servicios individualizados que reciben otros, como el suministro de agua (Kitchen, 2002: 147; Kitchen y Slack, 2016: 4); y en parte de la simple necesidad: el estancamiento de la base imponible del property tax, sumada a las dificultades políticas para elevar el tipo impositivo, determinan la incapacidad de este impuesto para allegar fondos suficientes para los crecientes gastos municipales. Si a esto se suman los límites normativos para el endeudamiento local y los enormes recortes en las transferencias provinciales desde 2005, el resultado final es que sólo las tasas por el uso o recepción de un servicio público local son una fuente fiable para un aumento de los ingresos locales (Mascarin y Williams, 2009: 98). Esta valoración crecientemente favorable de las tasas por servicios locales individualizables (y por tanto no por el disfrute de los llamados common goods) suscita objeciones de justicia social, precisamente por el carácter regresivo de las tasas (todos pagan el servicio al mismo precio, con independencia de su renta). Por eso se proponen tasas diferenciales para los menos pudientes o para altos niveles de uso o consumo (increasing block rates) (Tindal y Tindal, 2008: 244; Sancton, 2015: 309).

\$52 En el plano normativo, las anteriores consideraciones políticas y de necesidad tienen reflejo en la legislación de régimen local. En Canadá, las distintas leyes provinciales de régimen local directamente favorecen la imposición de tasas, frente a los impuestos. Se parte en las leyes provinciales de que todo impuesto grava inmediatamente la capacidad contributiva, mientras que la tasa (fee) se atiene estrechamente al coste por la prestación del servicio (Mascarin y Williams, 2009: 99). Sobre esta premisa, las leyes normalmente autorizan con carácter general la imposición de tasas locales ${ }^{45}$, siempre que se ciñan al coste del servicio ${ }^{46}$. Y sin em-

45 Por ejemplo: Section 8 Alberta Municipal Government Act 2000

46 Asi: Section 220 (1) Ontario Municipal Act 2001. 
REALA. Nueva Época - N.o 13, abril-septiembre 2020 - ISSN: 1989-8975 - DOI: 10.24965/reala.i13.10742 - [Págs. 22-46]

Gobiernos locales en Canadá y en España: lejos, pero no tanto

Francisco Velasco Caballero

bargo, las mismas leyes prohíben todo nuevo impuesto (o la modificación normativa de los existentes) que no esté expresa e inmediatamente autorizado por una ley, necesariamente provincial (Mascarin y Williams, 2009: 35). Este distinto régimen legal de las fees y los taxes se extrema en la jurisprudencia, que considera ultra vires y nula, por no tener cobertura en un Statute [ley parlamentaria] ni en las prerrogativas de common law, cualquier aparente tasa que, por no haberse calculado con rigor el coste efectivo del servicio, materialmente no es el pago por una prestación o servicio municipal, sino un impuesto ${ }^{47}$.

En apariencia, el régimen legal de las tasas locales en Canadá es considerablemente más sencillo que el que rige en España. Fundamentalmente, por su mayor contraposición a los impuestos (que están sometidos a mayores cautelas y límites). En apariencia, en España son mayores las exigencias legales para la imposición de tasas o precios por servicios públicos. Así resultaría de la inclusión de las tasas locales en el concepto de tributo, para el que rige reserva de ley (art. 131.1 y 2) y, complementariamente, de ordenanza fiscal (art. 20.1 LHL) ${ }^{48}$. Pero esta mayor rigidez legal para las tasas en España puede ser más aparente que real. Porque también en las provincias canadienses la creación de tasas locales está directamente autorizada por la ley (provincial) y la efectiva determinación de la tasa o precio en cada caso se aprueba -como todas las decisiones que afectan a los ciudadanos- necesariamente por ordenanza (bylaw) del pleno municipal.

$\$ 54$ Las transferencias son la tercera fuente de ingresos locales. Tanto en Canadá como en España las transferencias pueden ser condicionadas o incondicionadas. En términos cuantitativos, y conforme a los datos del anterior cuadro de ingresos (supra § 44), las transferencias son mucho más importantes en España que en Canadá. Si en las provincias canadienses las tasas son la segunda fuente de ingresos locales, esa segunda posición corresponde en España a las transferencias. Por cierto que en este punto los paneles numéricos de la OCDE ${ }^{49}$ son equívocos, pues computan como ingresos tributarios la participación de los municipios españoles en los rendimientos de los impuestos estatales como el IRPF y el IVA (conforme a los arts. 111 y 112 LHL), siendo esto más bien una transferencia estatal que un ingreso tributario municipal.

En el caso de Canadá, la mayoría de las transferencias provienen de cada provincia. Muy inferiores (aunque de importancia creciente) son las transferencias federales, normalmente condicionadas: para proyectos de infraestructuras con relevancia federal, o para actividades locales relacionadas con competencias federales (inmigración, lucha contra el cambio climático, etc.). Justamente a la inversa sucede con las transferencias en España. Las transferencias a los municipios proceden en su gran mayoría del Estado, siendo muy inferiores las subvenciones o transferencias autonómicas (tanto las «participaciones en los ingresos autonómicos» [PIA] como otras subvenciones normalmente condicionadas). De otro lado, en España las provincias se financian casi por entero mediante transferencias estatales, mientras que en Canadá el upper tier del gobierno local (comarcas, regiones, distritos metropolitanos) se financia con el mismo tipo de recursos que los municipios (esto es, a través de los rendimientos del property tax).

§56 La comparación entre transferencias muestra mayores simetrías en las condicionadas que en las incondicionadas. Tanto en Canadá como en España, las transferencias condicionadas frecuentemente están ligadas a concretas inversiones de capital (infraestructuras locales), aunque también son importantes las inversiones vinculadas a específicas actividades locales (como prestaciones asistenciales, transporte público urbano y políticas locales de vivienda). Y también en los dos países las subvenciones condicionadas son objeto de crítica, por limitativas de la autonomía local, por no responder al principio de conexión entre competencias y recursos financieros y por dificultar la responsabilidad democrática de los ayuntamientos ante sus electores (Tindal y Tindal, 2008: 224; Medina, 2003: 58).

$\$ 57$ Mayores son las diferencias en las transferencias incondicionadas. Fundamentalmente, porque en España estas subvenciones son un instrumento ordinario de financiación, que complementa estructuralmente los ingresos municipales provenientes de recursos propios (impuestos municipales y tasas, fundamentalmente). Cada municipio recibe transferencias en función de su población, tomando como año de referencia 2003. Este régimen de transferencias claramente favorece a los municipios más grandes ${ }^{50}$. Y no tiene en cuenta la mayor capacidad de autofinanciación mediante impuestos propios de los grandes municipios.

47 Así, en el Tribunal Supremo de Canadá: Allard Contractors Ltd. v Coquitton (District), [1993] 4 S.C.R. 371, 18 M.P.L.R (2d) 1. En los tribunales de Ontario: 1736095 Ontario Ltd. v Waterloo (City), [2015] O.J. No 5462, 46 M.P.L.R (Tth) 1 (Div. Ct); y Angus v Port Hope (Municipality), [2016] O.J No 3148, 2016 ONSC 3931 (S.C.J).

48 En este sentido, recientemente: STS 1015/2019, de 9 de julio de 2019.

49 OECD (2018), Revenue Statistics 2018, OECD Publishing, Paris, pág. 78. https://doi.org(10.1787/rev_stats-2018-en.

50 Informe de la Comisión de Expertos para la Revisión del Modelo de Financiación Local, Ministerio de Hacienda, julio de 2018, pág. 127 y ss. 
Como contrapunto, en las distintas provincias canadienses las transferencias incondicionadas están generalmente diseñadas para suplir la falta estructural de ingresos de los municipios pequeños y medianos, no el conjunto de los municipios. En efecto, dado que en Canadá las entidades locales son muy dependientes del property tax, los ingresos locales son muy limitados allí donde la base imponible del impuesto (determinada por la valoración catastral) es muy baja, y apenas se puede compensar con tipos impositivos altos. Esta circunstancia ha movido a las provincias a establecer diferentes instrumentos o programas de ecualización, mediante transferencias incondicionadas. Lo característico de estos programas es que sólo financian a una parte de los municipios (no a todos): sólo a los que por su singularidad económica, demográfica o geográfica tienen dificultades de autofinanciación (mediante el property tax). Un buen ejemplo de estos programas está en el Ontario Municipal Finance Partnership ${ }^{51}$. En 2019, este programa aporta subvenciones a un total de 389 entidades locales generales (municipios y comarcas, regiones o distritos) de los 414 que tiene la provincia. $Y$ entre ellos no están, lógicamente, ninguna de las grandes ciudades: ni Toronto, ni Mississauga, ni Hamilton, ni London. Otra característica notable del programa de subvenciones es que se articula a través de cuatro fondos, todos ellos complementarios y con criterios diferentes para la distribución. El Assessment Equalization Grant se fija en las valoraciones catastrales, asignando subvenciones a los municipios cuya suma de valores catastrales está por debajo de la media provincial. El llamado Northern Communities Grant es un fondo directamente destinado a los municipios más despoblados, que se encuentran en el norte de la provincia; el Rural Communities Grant se fija en el porcentaje de «ruralidad» de cada municipio (a más ruralidad, valorada en términos de densidad demográfica, mayores subvenciones); y finalmente el Northern and Rural Fiscal Circumstances Grant asigna subvenciones a aquellos municipios que tienen especiales dificultades financieras objetivas (por su localización, o el envejecimiento de su población, por ejemplo). Según lo expuesto, y tomando como referencia el ejemplo de Ontario, las transferencias provinciales incondicionadas sólo tienen una misión ecualizadora (para los municipios pequeños, rurales o remotos). No son una fuente estructural y lineal de financiación. Podría considerase que en España esta función ecualizadora la cumplen algunos programas coyunturales de subvenciones a los municipios rurales, que normalmente son condicionados, o la actividad de asistencia técnica y suplencia de las provincias (conforme al art. 36.1 b) LBRL). Aunque en este último caso hay que tener en cuenta que la provincia no tiene por destinatarios de su actividad sólo a los municipios medianos y pequeños (los inferiores a 20.000 habitantes) sino a todos los municipios provinciales, por lo que la asistencia y cooperación provincial no puede considerarse siempre como un instrumento indirecto de ecualización o nivelación financiera.

\$58 Por último, el crédito (borrowing) también es una fuente complementaria de ingresos locales ( $\mathrm{y}$ también un gasto, ya que los créditos han de devolverse con intereses). Diversas experiencias históricas de endeudamiento excesivo, e incluso de quiebra, han dado lugar a amplias prohibiciones y límites para el endeudamiento local, tanto en Canadá como en España. En Canadá, con carácter general, está fuertemente restringido el endeudamiento local para gasto corriente (operative) y está permitido con límites para la inversión de capital (Mascarin y Williams, 2009: 102) ${ }^{52}$. Reglamentos provinciales, expresamente autorizados por la ley, regulan con detalle estos límites ${ }^{53}$. Con algunas diferencias, también en España hay severos límites y controles sobre el endeudamiento (arts. 48 a $55 \mathrm{LHL}$ ), agravados a partir de la crisis financiera de 2007.

\section{REFERENCIAS BIBLIOGRÁFICAS}

AUBY, J. (2010): "Le droit administratif en Europe, 20 ans après", en European Review of Public Law / Revue European de Droit Publique, núm. 22, págs. 19-63.

BEL I QUERALT, G.; ESTRUCH MANJÓN, A. (2011): "La gestión de los servicios públicos locales: ¿Por qué se privatizan los servicios públicos y qué efectos tiene la privatización?”, en Anuario de Derecho Municipal, núm. 5, págs. 193-205.

51 https://www.fin.gov.on.ca/en/budget/ompf/2019/index.html. Para Alberta, véase también el Alberta Community Partnership (https://www.alberta.ca/alberta-community-partnership.aspx).

52 Para los municipios pequeños y medianos de Québec: article 1061 Code Municipal du Québec 1916; Para los municipios de Nova Scotia: Section 84 Nova Scotia Nova Municipal Government Act 1998.

53 Así, para Ontario: O. Regulation 403/02 (límites a los contratos de leasing); O. Regulation 276/02 (sobre créditos bancarios); O. Regulatioon 278/02 (sobre financiación de infraestructuras). Para Alberta, véase Sections 251 a 263 Alberta Municipal Government Act 2000. 
REALA. Nueva Época - N. 13, abril-septiembre 2020 - ISSN: 1989-8975 - DOI: 10.24965/reala.i13.10742 - [Págs. 22-46]

Gobiernos locales en Canadá y en España: lejos, pero no tanto

Francisco Velasco Caballero

BISH R. L.; CLEMENS, E. G. (2008): Local Government in British Columbia. Richmond: Union of British Columbia Municipalities.

BLACK, C. (2014): Rise To Greatness: The History of Canada from the Vikings to the Present. Toronto: McClelland \& Stewart.

BRIFFAULT, R.; REYNOLDS L. (2016): Cases and Materials on State and Local Government Law. St. Paul: West Academic.

CARRO FERNÁNDEZ-MAYOR, J. L. (2000): "La cláusula general de competencia municipal”, en Anuario del Gobierno Local, núm. 1, págs. 48-51.

RAIG, P. (2016): Administrative Law. London: Sweet and Maxwell.

DE LA SIERRA, S. (2016): "Límites y utilidades del derecho comparado en el derecho público. En particular, el tratamiento jurídico de la crisis económico-financiera", en Revista de Administración Pública, núm. 201, págs. 6999. DOI: $h$ ttps://doi.org/10.18042/cepc/rap.201.03.

DÍEZ SASTRE, S. (2009): "Entes locales, Constitución y federalismo canadiense”, en Revista Española de Derecho Constitucional, núm. 85 , págs. 217-251.

DUFF, D. (2004): "Benefit taxes and user fees in theory and practice", en University of Toronto Law Journal, vol. 54, núm. 4, págs. 391-447. DOI: https://doi.org/10.1353/tlj.2004.0013.

ESTEVE PARDO, J. (2010): “La recepción en la Europa continental del Derecho de la regulación de la economía”, en Revista de Administración Pública, núm. 183, págs. 295-307. DOI: https://doi.org/10.2307/j.ctvq2w2zd.8.

GARCEA, J.; LESAGE, E. C. (2008): "Local Government Reforms in Canada”, en Local Government Reform. A Comparative Analysis of Advanced Anglo-American Countries. Cheltenham: Edward Elgar.

GARCÍA ROCA, J. (2004): "Un bloque constitucional local conforme al principio de subsidiariedad (un desarrollo constitucional pendiente)", en Revista de Estudios de la Administración Local y Autonómica (REALA), núm. 294295, págs. 13-66. DOI: https://doi.org/10.24965/reala.vi294-295.9234.

GRAHAM, K. A.; PHILLIPS, S. D. (1998): Urban Governance in Canada. Toronto: Hartocurt Canada.

JIMÉNEZ ASENSIO, R. (2009): "La dirección pública profesional: perspectiva comparada y diagnóstico de la situación en España", en JIMÉNEZ ASENSIO, R.; VILLORIA MENDIETA, M.; PALOMAR OLMEDA, A. (eds.): La dirección pública profesional en España. Madrid-Barcelona-Buenos Aires: Marcial Pons e IVAP.

KISCHEL, U. (2015): Rechtsvergleichung. München: C. H. Beck.

KITCHEN, H. (2002): "Municipal Revenue and Expenditure Issues in Canada”, en Canadian Tax Papers, núm. 107.

KITCHEN, H.; SLACK, E. (2016): "More Tax Sources for Canada's Largest Cities: Why, What, and How", en IMFG Papers on Municipal Finance and Government, núm. 27, págs. 1-33.

KUSHNER, J.; SIEGEL, D. (2006): "Why Do Municipal Electors Not Vote?”, en Canadian Journal of Urban Research, vol. 15, núm. 2, págs. 264-277.

LADNER, A.; KEUFFER, N.; BALDERSHEIM, H.; HLEPAS, N.; SWIANIEWICZ, P.; STEYYERS, K.; NAVARRO, C. (2019): Governance and Public Management. New York: Palgrave Macmillan.

LÓPEZ RAMÓN, F. (2010): "Políticas ante la fragmentación del mapa municipal”, en Revista de Estudios de la Administración Local y Autonómica (REALA), núm. 313-314, págs. 67-104. DOI: https://doi.org/10.24965/reala. vi313-314.9923.

MARTÍNEZ SÁNCHEZ, C. (2014): El principio de equivalencia en el sistema tributario español. Madrid: Marcial Pons.

MASCARIN J.; WILLIAMS, C. J. (2009): Ontario Municipal Act and Commentary. Toronto: Lexis Nexis Canada.

MCMILLAN, M.; DAHLBY, B. (2014): "Do local governments need alternative sources of tax revenue? An assessment of the options for Alberta cities", en SSP Research Papers, vol. 7, núm. 26, págs. 1-35.

MEDINA GUERRERO, M. (2003): "Los recursos financieros de las diputaciones provinciales y la relación con su régimen competencial”, en CAAMAÑO DOMÍNGUEZ, F. (ed.): La autonomía de los entes locales en positivo. Barcelona: Fundación Democracia y Gobierno Local.

MELOCHE, J.; VAILLANCOURT, F. (2013): "Public Finance in Montréal: In Search of Equity and Efficiency", en IMFG Papers on Municipal Finance and Government, núm. 15, págs. 1-32.

NAVARRO, C.; VELASCO CABALLERO, F.; ZAGÖRSKI P. (2019): "Cuarenta años de elecciones municipales: el sistema electoral y su rendimiento", en Anuario de Derecho Municipal, núm. 12, págs. 23-49.

ORTEGA, L. (2000): "Las competencias como paradigma de la autonomía local", en Justicia Administrativa, núm. Extraordinario, págs. 33-54.

PAREJO ALONSO, L. (2004): "Una visión sobre el gobierno local”, en Anuario del Gobierno Local, núm. 1, págs. 55-96.

RODRÍGUEZ DE SANTIAGO, J. M. (2010): "Posición constitucional de los gobiernos locales", en VELASCO CABALLERO, F. (ed.): Gobiernos locales en Estados federales y descentralizados: Alemania, Italia y Reino. Barcelona: Institut d'Estudis Autonòmics.

SANCHEZ MORÓN, M. (2018): Las Administraciones españolas. Madrid: Tecnos.

SANCTON, A. (2000): Merger Manía. Kingston: McGill Queen's University.

SANCTON, A. (2015): Canadian Local Governments. An Urban Perspective. Don Mills: Oxford University Press, $2 .^{a}$ ed.

SCHMIDT-ASSMANN, E. (2018): "Zum Standort der Rechtsvergleichung", en Verwaltungsrecht. Zeitschrift für Ausländisches Öffentliches Recht und Völkerrecht, núm. 78, págs. 807-862. 
SLACK, E.; BIRD, R. (2013): “Merging Municipalities: Is Bigger Better?”, en IMFG Papers on Municipal Finance and Government, núm. 14, págs. 1-34.

SMITH, D. E. (2010): Federalism and the Constitution of Canada. Toronto: Universitiy of Toronto Press.

TINDAL, C. R.; TINDAL, S. (2008): Local Government in Canada. Toronto: Nelson Education, 7. . ed.

VELASCO CABALLERO, F. (2009): Derecho local. Sistema de fuentes. Madrid-Barcelona-Buenos Aires: Marcial Pons.

VELASCO CABALLERO, F. (2013): "Planta local y entidades locales inframunicipales en Europa", en OLIVEIRA, A. C. (ed.): A Reforma do Estado e a Freguesia. Braga: Nedal.

VELASCO CABALLERO, F. (2014): "Desarrollos normativos autonómicos de la Ley de Racionalización y Sostenibilidad de la Administración Local”, en Anuario de Derecho Municipal, núm. 8, págs. 22-53.

VELASCO CABALLERO, F. (2018): "Derecho urbanístico y envejecimiento demográfico", en InDret, núm. 4, págs. 1-55.

VELASCO CABALLERO, F. (2019): “Metodología comparada para el Derecho Administrativo", en Revista Española de Derecho Administrativo, núm. 200, págs. 51-76.

WILSON, D.; GAME, C. (2011): Local Government in the United Kingdom. New York: Palgrave.

YOUNG, R. (2009): "Canada", en STEYTLER, N. (ed.): Local Government and Metropolitan Regions in Federal Systems. Montréal and Kingston: McGill-Queen's University Press. 